\title{
Parametric study and formulae of SCFs for positive large eccentricity CHS N-joints
}

\author{
Yu Chen*, Jian Yang, Kang Hu \\ School of Urban Construction, Yangtze University, Jingzhou, China (434023)
}

\begin{abstract}
This paper put forward the importance of stress concentration factors (SCF) of positive large eccentricity CHS N-joints under compression in vertical brace although the static behavior of the $\mathrm{N}$-joints has been researched. The four positive large eccentricity CHS N-joints were first tested for the verification and calibration of finite element (FE) models. As eccentricity increased, the experimental results and FE analysis showed that the position of maximum SCF moved from the crown heel point to the saddle point at the chord and vertical brace intersection. At the inclined brace and chord intersection, the position of maximum SCF moved from the saddle point to the crown toe point with the decrease of eccentricity. A set of parametric formulae was proposed to predict the SCFs of positive large eccentricity CHS N-joints based on 256 FE models. For positive large eccentricity CHS N-joints, SCF increased as $\tau$ increased. As $\beta$ and $2 \gamma$ increased, SCF distribution was complex. SCF linearly increased with the increase of eccentricity to chord diameter ratio $(\varepsilon)$ at the chord and vertical brace intersection welding seam. SCF of $\mathrm{N}$-joint around inclined brace and chord intersection increased when the value of $\theta$ increased. The assessment of the proposed formulae and CIDECT formulae were based on the database of FE analysis results. Simple method for predicting SCFs of positive large eccentricity CHS N-joints given in CIDECT was unreliable. The new formulae of SCFs were proposed for positive large eccentricity CHS N-joints under axial loading, which were verified to be accurate and reliable.
\end{abstract}

Keywords: Stress concentration factors; Positive large eccentricity CHS N-joints; Finite element analysis; Parametric study; Formulae

\footnotetext{
*Corresponding author at: School of Urban Construction, Yangtze University, Jingzhou 434023, China. Tel.: +86 18030219629. E-mail address: kinkingingin@163.com (Y. Chen).
} 


\section{Introduction}

In onshore and offshore structures, the application of positive large eccentricity CHS N-joints whose eccentricity ratio (eccentricity to chord diameter ratio) is larger than 0.25 are common in order to avoid forming partially or completely overlapped CHS joints, as shown in Fig. 1. Currently, the positive large eccentricity CHS N-joint is traditionally treated as two separate CHS Y-joint configurations with the use of parametric formulae for simple Y-joints design. In this paper, SCF formulae of positive large eccentricity CHS N-joints were obtained from extensive parametric numerical analysis verified by experimental results.

Extensive researches have been conducted in recent years on stress concentration factors of non-eccentricity and small eccentricity CHS and RHS joints. Parametric study on SCFs for multi-planar CHS XX-joints was conducted by Chiew et al. [1]. A set of simplified formulae of CHS and RHS K- and KK-joints was proposed by Wingerde et al. [2]. Stress concentration factors of doubler plate reinforced CHS T-joints under axial tension, axial compression, in-plane and out-of-plane bending were numerically investigated by Fung et al. [3]. Fatigue tests were conducted on welded thin-walled T-joints made of CHS braces welded onto SHS chords under in-plane bending in the brace by Mashiri et al. [4]. Stress intensity factors along the crack propagation of welding seam and steel material were evaluated by Shao and Lie [5]. SCFs of notched CHS T-joints were numerically investigated by Diaye et al. [6]. Gao and Gho [7] put forward a set of parametric formulae to predict SCF at the hot spot of negative completely overlapped CHS N-joints under lap brace axial compression. The negative completely $\mathrm{N}$-joint specimen comprised a horizontal $219.1 \mathrm{~mm}$ diameter chord, a $30^{\circ}$ diagonal through brace and a vertical lap brace. It was specifically designed to have an eccentricity ratio of -0.65 . Lotsberg [8] put forward new modification about SCF formulae of CHS T- and Y-joints to make it simpler to include effect of joints flexibility. Experimental and numerical investigations on SCFs of cold formed stainless steel SHS and RHS $\mathrm{X}$-joints were conducted by Feng and Young [9]. A series of fatigue tests was conducted to measure the SCFs of diamond bird-beak T-joints in a reasonable range of parameters by Tong et al. [10]. A new approach to estimate fatigue strength of CHS joints was proposed by Liu et al. [11]. SCFs of thin-walled concrete-filled CHS joints subjected to axial tension loading were experimentally investigated by $\mathrm{Xu}$ and Chen [12]. 
The previous literatures were mainly focused on SCFs of non-eccentricity and small eccentricity CHS and RHS joints. Although the static behavior of positive large eccentricity CHS N-joints has been experimentally researched by Chen et al. [13], there is little research being carried out on fatigue behavior of the positive large eccentricity $\mathrm{N}$-joints under axial loading. The stress distribution of the positive large eccentricity $\mathrm{N}$-joints tests calibrating the corresponding FE models with welding seams was not reported. Consequently, the SCFs distribution of positive large eccentricity $\mathrm{N}$-joints under compression in vertical brace was experimentally researched. FEA parametric analysis was also carried out to investigate the effects of geometric parameters on the SCFs of positive large eccentricity N-joints. Lastly, the SCF formulae were also put forward for positive large eccentricity $\mathrm{N}$-joints under axial loading.

\section{Experimental investigation}

\subsection{Experimental design}

Four positive large eccentricity $\mathrm{N}$-joints under vertical brace axial compression within the elastic limit of material was tested. The stress concentration factor testing of the positive large eccentricity $\mathrm{N}$-joints specimen was carried out in the Civil Engineering Experimental Teaching Center, School of Urban Construction, Yangtze University. The photo of typical joint specimen was shown in Fig. 2. A positive large eccentricity $\mathrm{N}$-joints comprise a horizontal $\mathrm{CHS}$ chord without additional axial loading, a inclined CHS brace under tension and a vertical CHS brace under compression. The geometrical properties of the joint specimen are summarized in Table 1. Geometric parameters $\beta=d_{1} / d_{0}, \tau=t_{\mathrm{i}} / t_{0}, 2 \gamma=d_{0} / t_{0}$ and $\varepsilon=e / d_{0}$ are summarized in Fig. 1, using the dimensions of all specimens as detailed in Table 1. The joint specimens were fabricated on the basis of structural steel tubes API 5L [14] grade B and welded according to the requirement specified by CIDECT [15]. The welding at the intersections of the chord and inclined brace and at the intersections of the chord and vertical brace was complete penetration groove weld with standard profile. In the set up of the test specimen, the ends of chord and inclined brace were welded onto the $10 \mathrm{~mm}$ thickness flat end plates and bolted directly onto the steel truss to generate a pinned support of chord and inclined brace. In order to form positive large eccentricity at the joint intersections, eccentricity $(e)$ of all specimen joints was greater than $35 \mathrm{~mm}$. 


\subsection{Joints specimen label}

The specimens are labeled on the basis of their cross-section property, joint configuration and eccentricity ratio. For example, the label 'CHS-N-ER-0.25' defines the following N-joint as follows:

- The first group of letters 'CHS' denotes Circular Hollow Section.

- The second letter ' $\mathrm{N}$ ' denotes $\mathrm{N}$-joint.

- The third group of letters 'ER' denote ratio of positive eccentricity to diameter of chord and the following expression ' 0.25 ' indicates the value of eccentricity ratio. Experimental value of eccentricity ratio varied from 0.25 to 1.00 including four levels.

The chord member of all specimens is circular hollow section of CHS140×4.0, which having the nominal diameter $\left(d_{0}\right)$ of $140 \mathrm{~mm}$, and the nominal wall thickness $\left(t_{0}\right)$ of $4.0 \mathrm{~mm}$. The inclined brace member of all specimens is circular hollow section of CHS114×3.0, which having the nominal diameter $\left(d_{1}\right)$ of $114 \mathrm{~mm}$, the nominal wall thickness $\left(t_{1}\right)$ of $3.0 \mathrm{~mm}$ and inclined angle $(\theta)$ of $45^{\circ}$. The vertical brace member of all specimens is circular hollow section of CHS89 $\times 2.0$, which having the nominal diameter $\left(d_{2}\right)$ of $89 \mathrm{~mm}$, and the nominal wall thickness $\left(t_{2}\right)$ of $2.0 \mathrm{~mm}$.

\subsection{Loading}

Axial compression force was applied to the vertical brace of positive large eccentricity $\mathrm{N}$-joints by using a 100kN servo-controlled hydraulic testing machine. In order to drive the hydraulic actuator at a constant stable speed of $1 \mathrm{kN} / \mathrm{min}$ for all test specimens, load control was used in the tests. In the final experiments, the hydraulic actuator was controlled to the predetermined loads, and then kept the predetermined applied loads for about 2 minutes, the strain gauges readings were recorded automatically by 3816 signal collection system. The applied loads were increased to the next load level till final loading. A photograph of the test rig of strain concentration factors measurements for positive large eccentricity $\mathrm{N}$-joints was shown in Fig. 3.

\subsection{Gradient strain gauges location}

According to the recommendation from CIDECT [15], position of gradient strain gauges and the extrapolation region to determine the hot spot stress of the joints were designed, as shown in Fig. 4. At the two braces and chord intersections the gradient gauges were placed perpendicular to the 
welding seam at $90^{\circ}$ interval. The strain gauges were bonded half the perimeter of the joints. A total of 12 gradient strain gauges including 6 strain gauges at the chord and inclined brace intersection and 6 strain gauges at the chord and vertical brace intersection were bonded on the surface of steel tube around two intersections.

\subsection{Material properties}

All specimens were fabricated by using Q235B (nominal yield stress=235MPa) steel tube. The material properties obtained from the tensile coupon tests are summarized in Table 2, which include the elastic modulus $(E)$, tensile yield stress $\left(f_{\mathrm{y}}\right)$, ultimate tensile stress $\left(f_{\mathrm{u}}\right)$, and elongation after fracture $\left(\varepsilon_{\mathrm{f}}\right)$.

\subsection{Experimental results}

For positive large eccentricity CHS N-joints, the quadratic extrapolation method can be used to calculate SCFs of joints because the gradient strain at the intersection is non-linear. The boundaries of the extrapolation region for positive large eccentricity CHS N-joints are defined in Fig. 5. The extrapolation points must be positioned in such a way that the strain gradients due to the global geometry effects are represented. Quadratic extrapolation methods are used for the determination of the hot spot stress of positive large eccentricity CHS N-joints, as shown in Fig. 5.

All the strain gauges were placed perpendicular to the welding seam. The SCF values obtained from the respective strain gauges bonded on the crown and saddle point positions in the experimental joints are shown in Fig. 6. X-axial degree represents strain gauge numbers on chord or braces in Fig. 6, as shown in Fig. 4. Experimental results have been fitting curves between the measured SCFs by using smoothing spline. As eccentricity decreased, the position of maximum SCF moved from the saddle point to the crown heel point at the chord and vertical brace intersection welding seam near the vertical brace, as shown in Fig. 6a. As shown in Fig. 6b, the curves of the stress concentration factor values were parabolic curves. The maximum stress concentration factor occurred on near saddle point at the chord and vertical brace intersection welding seam near the chord intersecting line. At the chord and inclined brace intersection welding seam near the inclined brace intersecting line, the curves of the stress concentration factor values were parabolic curves on the inclined brace side, as shown in Fig. 6c. The maximum stress concentration occurred on near the crown toe point of 
inclined brace. As shown in Fig. 6d, the curves of the stress concentration factor values were linear on the chord side. At the chord and inclined brace intersection welding seam near the chord intersecting line, the maximum stress concentration occurred on near the crown toe point of chord.

\section{Validation of FEA model}

\subsection{Finite element model}

The FEA software ABAQUS was applied for the numerical investigation SCF distribution of positive large eccentricity CHS N-joints under compression in vertical brace [16]. The steel material properties and cross-section dimensions obtained from the experiments were used in the FEA. In order to model the positive large eccentricity CHS N-joints, three-dimensional eight-node solid element C3D8I was used in this numerical study. The welding seams were only considered geometrical influences in the finite element models on the SCF distribution of the joints. The solid models of N-joints are shown in Fig. 7a-b. The finite element meshes of joints are shown in Fig. 7c for positive large eccentricity CHS N-joints. Convergence study was carried out in the paper by comparing FEA results considering layer of tube and welding seam and element number with test results. A convergence study is conducted to obtain a suitable mesh size for modelling the positive large eccentricity CHS N-joint specimens before the FE model is used to carry out the following analyses.

The tubes of joints were divided into three layers in the thickness direction in the FEA models, as shown in Fig. 7d. The welding seams were divided into six layers in the FEA models, as shown in Fig. 7e-f. It was found that the three-element mesh density in the thickness direction of chord, inclined brace and vertical brace, meanwhile, the six-element mesh density of the chord and inclined brace intersection welding seam and of the chord and vertical brace intersection welding seam could achieve accurate results with minimum computational time by using FEA validation. Finite element analysis of the four specimens was carried out in accordance with the above mesh density of finite element simulation. Loading and boundary conditions were the same with the test. Symmetrical constraints were applied to all nodes lying in the plane of symmetry. Both ends of the chord and the braces were pinned to simulate the boundary conditions in the test by releasing rotation constraints of hole in end plates of chord and inclined brace. Compressive force in vertical brace was simulated as 
surface press in FEA model.

Chord and two braces members far from intersection welding seams were coarsely meshed, while the welding seams intersection area were finely meshed. The width and length of control element of chord, inclined and vertical braces far from welding seam intersection were arranged at about $5 \mathrm{~mm}$. The width and length of control element of welding seams at the intersections were arranged at about $0.5 \mathrm{~mm}$. The total number of elements in a positive large eccentricity $\mathrm{CHS} \mathrm{N}$-joints FE model was about 25000. The number of elements of two welding seams intersection was about $35 \%$ of total element number of joints.

\subsection{Validation Results}

The stress distribution of the four positive large eccentricity CHS N-joints was observed in the finite element models, as shown in Fig. 8a-d, respectively. As eccentricity increased, the experimental results showed that the position of maximum SCF moved from the crown heel point to the saddle point at the chord and vertical brace intersection. As the eccentricity decreased, the experimental results showed that the position of maximum SCF moved from the saddle point to the crown heel point at the chord and vertical brace intersection welding seam. Similarity, at the inclined brace and chord intersection welding seam, the position of maximum SCF moved from the saddle point to the crown toe point with the decrease of eccentricity.

The comparisons between the experimental and the FEA results were carried out based on the SCFs at chord and vertical brace intersection welding seam and at inclined brace and chord intersection welding seam of the specimens. The nominal stress was calculated based on the nominal strain without primary bending moments. Meanwhile, according to the actual Young's modulus, axial compressive value and cross-sectional area of the vertical brace, the nominal stress can be calculated without geometric and material non-linearity. Elements with reduced integration were used in FEA. The SCF comparison results of the four experimental CHS N-joint are shown in Fig. 9.

SCF distribution from FEA fundamentally agreed with the test result, as shown in Fig. 9. The finite element models were also verified by the curve of the SCF values of the positive large eccentricity CHS N-joints achieved in the experimental results. Therefore, the newly calibrated FE models successfully predicted the SCF distribution of the positive large eccentricity CHS N-joints under compression in vertical brace. 


\section{Parametric study}

\subsection{Parameters}

After the finite element model was verified by the experimental results of SCF distribution, the effects of the geometry parameters on the SCFs of the positive large eccentricity CHS N-joints were numerically investigated. The configuration and boundary condition of the joints model was the same with configuration and boundary condition of the test specimens. The dimensionless parameters studied in the paper were $\beta, 2 \gamma, \tau$ and $\varepsilon$. The practical parameters ranges in parametric study were referenced to recommendations API RP2A (1993) [14]. In addition, eccentricity ratio was designed be larger than 0.25 due to positive large eccentricity CHS $\mathrm{N}$-joints definition. In order to investigate on effects of $\beta, 2 \gamma, \tau$ and $\varepsilon$ on SCFs of positive large eccentricity CHS N-joints, the rest of the parameters was defined as following,

$$
\begin{array}{ll}
\theta=45^{0} & \text { Inclined brace angle is } 45^{\circ} \\
t_{0}=6 \mathrm{~mm} & \text { Chord wall thickness is } 6 \mathrm{~mm} \\
t_{1}=t_{2} & \text { Vertical brace and inclined brace wall thickness are same } \\
d_{2}=d_{1} & \text { Vertical brace diameter and inclined brace diameter are same } \\
L_{0}=2000 \mathrm{~mm} & \text { Chord length is } 2000 \mathrm{~mm} \\
L_{1}=1000 \mathrm{~mm} & \text { Inclined brace length is } 1000 \mathrm{~mm} \\
L_{2}=800 \mathrm{~mm} & \text { Vertical brace length is } 800 \mathrm{~mm} \\
N=10 \mathrm{kN} & \text { Axial compressive load in vertical brace is } 10 \mathrm{kN}
\end{array}
$$

$256 \mathrm{~N}$-joints with dimensionless parameter were analyzed to obtain the SCF values, as shown in Table 3. The identical element type, mesh size and material modeling of steel tubes used in the validation study were also employed in the parametric study. The $\mathrm{N}$-joints at the one end of chord and inclined brace were modeled by using the pinned connection in the parametric study.

\subsection{Parametric analysis results}

The numerical study for the development of SCF parametric formulae adopts a non-linear regression curve fitting program. The dimensionless parametric equations of SCF included four dimensionless parameters namely $\tau, \beta, 2 \gamma$ and $\varepsilon$.

The positions of maximum SCF of joints from finite element analysis were the same with the 
experimental results. As eccentricity decreased, the position of maximum SCF moved from the saddle point to the crown heel point at the chord and vertical brace intersection welding seam near the vertical brace intersecting line or the chord intersecting line based on FEA results. Similarity, at the inclined brace and chord intersection welding seam near the chord intersecting line or the inclined brace intersecting line, the position of maximum SCF moved from the saddle point to the crown toe point with the decrease of eccentricity. For positive large eccentricity CHS N-joints, SCF linearly increased as $\tau$ increased, as shown in Fig. 10. As $\beta$ increases, SCF distribution was complex as shown in Fig. 11. SCF increased as $2 \gamma$ increased at the chord and vertical brace intersection welding seam near the vertical brace intersecting line or the chord intersecting line, as shown in Fig. 12a-b. As $2 \gamma$ increases, SCF distribution was complex at the inclined brace and chord intersection welding seam near the chord intersecting line or the inclined brace intersecting line, as shown in Fig. 12c-d. As shown in Fig. 13a-b, SCF linearly increased with the increase of $\varepsilon$ at the chord and vertical brace intersection welding seam near the vertical brace intersecting line or the chord intersecting line. SCF increased with the increase of $\varepsilon$ at the inclined brace and chord intersection welding seam near the chord intersecting line, as shown in Fig. 13d.

A total of $28 \mathrm{FE}$ models of the positive large eccentricity CHS N-joints with different inclined angle of inclined brace are analyzed to investigate the effect of inclined angle $(\theta)$ on SCF at the inclined brace and chord intersection welding seam near the chord intersecting line or the inclined brace intersecting line. Brace width to chord width ratio $(\beta)$, chord width to wall thickness ratio $(2 \gamma)$ and eccentricity ratio $(\varepsilon)$ are set to be a constant value of $0.6,35$ and 0.5 , respectively. The values of $\theta$ take five different values of $30^{\circ}, 35^{\circ}, 40^{\circ}, 45^{\circ}, 50^{\circ}, 55^{\circ}$ and $60^{\circ}$. Fig. 14 shows the effect of $\theta$ on SCF of positive large eccentricity CHS N-joint around inclined brace and chord intersection. It can be seen that SCF of positive large eccentricity CHS N-joint around inclined brace and chord intersection increased when the value of $\theta$ increased.

\section{SCF formulae of joints}

Previously, a positive large eccentricity CHS N-joints was simply treated as two separate Y-joint. SCFs of positive large eccentricity CHS N-joints could be calculated by using SCF formulae of Y-joints with inclined brace or vertical brace given in the CIDECT Design Guide No.8 [15]. The comparison between CIDECT calculation results and FE parametric study result is shown in Table 4. 
According to the results of the comparison, the statistics of SCFs from CIDECT to finite element analysis SCFs results ratio are shown in Table 4.

According to the results of the comparison, SCFs for positive large eccentricity CHS N-joints under axial loading at the chord and vertical brace intersection welding seam near the vertical brace intersection line or the chord intersection line obtained by using CIDECT formulae were far less than SCFs in FE results. Hence, the fatigue life of positive large eccentricity CHS N-joints under axial loading at the chord and vertical brace intersection welding seam obtained by using the S-N curve given in the CIDECT was dangerous. Simultaneously, SCFs for positive large eccentricity CHS $\mathrm{N}$-joints under axial loading at the inclined brace and chord intersection welding seam near the chord intersection line or the inclined brace intersection line obtained by using CIDECT formulae were much greater than SCFs in FE results. The fatigue life of positive large eccentricity CHS N-joints under axial loading at the chord and vertical brace intersection welding seam obtained by using the $\mathrm{S}-\mathrm{N}$ curve given in the CIDECT was conservative.

Every proposed SCF formulae included four dimensionless parameters namely $\varepsilon, \beta, 2 \gamma, \tau$ and $\theta$. Multiple regression analysis was carried out by using SPSS program. The proposed formulae could predict SCFs of the positive large eccentricity CHS N-joints under compression in vertical brace, including the four SCF formulae at the chord and vertical brace intersection welding seam near the vertical brace intersecting line and the chord intersecting line and at the inclined brace and chord intersection welding seam near the chord intersecting line and the inclined brace intersecting line.

Based on the analysis results, the SCF formulae for the positive large eccentricity CHS N-joints under compression in vertical brace at the chord and vertical brace intersection welding seam near the vertical brace intersecting line or the chord intersecting line can be expressed as:

$$
\begin{aligned}
\mathrm{SCF}=0.39\left(1.97-1.57 \beta^{0.25}\right)(2 \gamma)^{0.80} \tau^{0.55} \varepsilon^{0.12} & \text { Vertical brace intersecting line } \\
\mathrm{SCF}=0.25\left(0.67-\beta^{2}+1.16 \beta\right)(2 \gamma) \tau^{0.90} \varepsilon^{0.29} & \text { Chord intersecting line }
\end{aligned}
$$

Based on the analysis results, the SCF formulae for the positive large eccentricity CHS N-joints under compression in vertical brace at the inclined brace and chord intersection welding seam near the chord intersecting line or the inclined brace intersecting line can be expressed as:

$$
\begin{aligned}
& \text { SCF }=0.154(\sin \theta)^{0.7}\left(1.97-1.57 \beta^{0.25}\right)(2 \gamma)^{0.9} \tau^{0.6} \varepsilon^{-0.17} \text { Inclined brace intersecting line } \\
& \mathrm{SCF}=0.00048(\sin \theta)^{0.7}\left(0.67-\beta^{2}+1.161 \beta\right)(2 \gamma)^{2.6} \tau^{1.25} \varepsilon^{-0.22} \quad \text { Chord intersecting line }
\end{aligned}
$$

The scope of the above formulae is: $0.3 \leq \beta \leq 0.6,24 \leq 2 \gamma \leq 60,0.25 \leq \tau \leq 1.00,0.3 \leq \varepsilon \leq 0.9,30^{\circ} \leq \theta \leq 60^{0}$. 
A comparison between the SCF calculated from proposed formulae and finite element analysis results was carried out. According to the results of the comparison, the statistics of SCF proposed formulae calculation to finite element analysis results ratio are shown in Table 5.

A good agreement was obtained with the mean SCF values of proposed formulae calculation-to-FEA values ratios of 1.027, 1.048, 1.084 and 1.087, and the corresponding coefficients of variation (COVs) of $0.027,0.051,0.097$ and 0.172 , for the chord and vertical brace intersection welding seam near the vertical brace intersecting line, the chord and vertical brace intersection welding seam near the chord intersecting line, the inclined brace and chord intersection welding seam near the inclined brace intersecting line and the inclined brace and chord intersection welding seam near the chord intersecting line, respectively. Therefore, the proposed formulae of SCFs were verified to be accurate and reliable for positive large eccentricity CHS N-joints under axial loading.

\section{Conclusions}

Experimental and numerical investigations on the SCF of the positive large eccentricity CHS $\mathrm{N}$-joints under compression in vertical brace were conducted in this study. According to the experimental and numerical investigations, main concludes as follows:

(1) As eccentricity decreased, the position of maximum SCF moved from the saddle point to the crown heel point at the chord and vertical brace intersection welding seam.

(2) At the inclined brace and chord intersection welding seam, the position of maximum SCF moved from the saddle point to the crown toe point with the decrease of eccentricity.

(3) SCF linearly increased with the increase of eccentricity ratio at the chord and vertical brace intersection welding seam.

(4) The fatigue life of positive large eccentricity CHS N-joints obtained by using simple method in CIDECT at the chord and vertical brace intersection welding seam was dangerous, while at the chord and vertical brace intersection welding seam was conservative.

(5) SCF formulae for the positive large eccentricity CHS N-joints under axial loading are reliable and safe in the defined boundary conditions.

\section{Acknowledgements}

This experimental and numerical research was supported by the National Science Foundation of China (Nos. 51278209 and 51478047). 
Nomenclature

$d_{0} \quad$ Diameter of chord

$d_{1}$ Diameter of inclined brace

$d_{2}$ Diameter of vertical brace

$t_{0} \quad$ Thickness of chord

$t_{1} \quad$ Thickness of inclined brace

$t_{2}$ Thickness of vertical brace

$e$ Eccentricity

$f_{\mathrm{u}} \quad$ Ultimate stress

$f_{\mathrm{y}} \quad$ Yield stress

$f_{\mathrm{y} 0} \quad$ Yield stress of the chord

$N \quad$ Axial load

$w \quad$ Weld size

$v$ Poisson's ratio

E Young's modulus

$\beta$ Brace width to chord width ratio $\left(b_{1} / b_{0}\right)$

$2 \gamma$ Chord width to wall thickness ratio $\left(b_{0} / t_{0}\right)$

$\tau$ Brace thickness to chord wall thickness ratio $\left(t_{1} / t_{0}\right)$

$\varepsilon$ Eccentricity ratio $\left(e / d_{0}\right)$

$\theta$ Inclined angle

\section{References}

[1] Chiew SP, Soh CK, Wu NW. General SCF design equations for steel multiplanar tubular XX-joints. International Journal of Fatigue 2000;22:283-293.

[2] Wingerde AM, Packer JA, Wardenier J. Simplified SCF formulae and graphs for CHS and RHS K- and KK-connections. Journal of Constructional Steel Research 2001; 57:221-252.

[3] Fung TC, Soh CK, Chan TK, Erni. Stress Concentration factors of doubler plate reinforced tubular T Joints. Journal of Structural Engineering 2002; 128:1399-1412.

[4] Mashiri FR, Zhao XL, Grundy P. Stress concentration factors and fatigue behaviour of welded 
thin walled CHS-SHS T-joints under in-plane bending. Engineering Structures 2004; 26:1861-1875. [5] Shao YB, Lie ST. Parametric equation of stress intensity factor for tubular K-joint under balanced axial loads. International Journal of Fatigue 2005;27:666-679.

[6] Diaye AN, Hariri S, Pluvinage G, Azari Z. Stress concentration factor analysis for notched welded tubular T-joints. International Journal of Fatigue 2007;29:1554-1570.

[7] Gao F, Gho WM. Parametric equations to predict SCF of axially loaded completely overlapped tubular circular hollow section joints. Journal of Structural Engineering 2008; 134:412-420.

[8] Lotsberg I. On stress concentration factors for tubular Y- and T-Joints in frame structures. Marin Structures 2011; 24:60-69.

[9] Feng R, Young B. Stress concentration factors of cold-formed stainless steel tubular X-joints. Journal of Constructional Steel Research 2003; 91:26-41.

[10] Tong LW, Fu YG, Liu YQ, Zhao XL. Stress concentration factors of diamond bird-beak SHS T-joints under brace loading. Thin-Walled Structures 2014; 74:201-212.

[11] Liu G, Liu YF, Huang Y. A novel structural stress approach for multiaxial fatigue strength assessment of welded joints. International Journal of Fatigue 2014;63:171-182.

[12] Xu F, Chen J, Jin WL. Experimental investigation of SCF distribution for thin-walled concrete-filled CHS joints under axial tension loading. Thin-Walled Structures 2015; 93:149-157.

[13] Chen Y, Liu FF. Experimental research on static behavior of big eccentric circular hollow section $\mathrm{N}$-joints with vertical brace under compression in symmetrical pratt truss. Engineering Mechanics 2011; 28:170-177. (in Chinese)

[14]Recommended Practice for Planning, Designing and Constructing Fixed Offshore Platforms-Working Stress Design, American Petroleum Institute: 2005.

[15] Zhao XL, Herion S, Packer JA, Puthli R, Sedlacek G, Wardenier J et al. Design guide for circular and rectangular hollow section joints under fatigue loading. CIDECT. 2001, IIW Doc. XV-EE-98-236.

[16] ABAQUS. Standard user's manual. Version 6.11. Hibbitt, Karlsson and Sorensen, Inc. Vols. 1-3, Version 6.11. USA. 2006. 


\section{LIST OF TABLES}

Table 1 Geometric parameters of positive large eccentricity CHS joints specimen Table 2 Basic material mechanical properties

Table 3 Parametric study results

Table 4 Comparison of CIDECT formulae calculation with FEA results for positive large eccentricity tubular $\mathrm{N}$-joints

Table 5 Comparison of proposed formulae calculation with FEA results for positive large eccentricity tubular $\mathbf{N}$-joints 


\section{LIST OF FIGURES}

Fig. 1. Positive large eccentricity CHS N-joints under axial loading

Fig. 2. Photo of positive large eccentricity $\mathrm{N}$-joints under axial loading

Fig. 3. Test rig

Fig. 4. Gradient strain gauges at intersections of $\mathrm{N}$-joints

Fig. 5. Definition of extrapolation region of positive large eccentricity CHS

N-joints

Fig. 6. SCF of experimental joints

Fig. 7. Finite element model of CHS N-joints

Fig. 8. Stress distribution of experimental $\mathrm{N}$-joints

Fig. 9. Comparison of test with FEA SCF

Fig. 10. Curves of SCF- $\tau$

Fig. 11. Curves of SCF- $\beta$

Fig. 12. Curves of SCF-2 $\gamma$

Fig. 13. Curves of SCF- $\varepsilon$

Fig. 14. Curves of SCF- $\theta$ 
Table 1 Geometric parameters of positive large eccentricity CHS joints specimen

\begin{tabular}{|c|c|c|c|c|c|c|c|c|c|}
\hline $\begin{array}{l}\text { Specimen } \\
\text { number }\end{array}$ & $\begin{array}{c}d_{0} \\
(\mathrm{~mm})\end{array}$ & $\begin{array}{c}d_{1} \\
(\mathrm{~mm})\end{array}$ & $\begin{array}{c}d_{2} \\
(\mathrm{~mm})\end{array}$ & $\begin{array}{c}t_{0} \\
(\mathrm{~mm})\end{array}$ & $\begin{array}{c}t_{1} \\
(\mathrm{~mm})\end{array}$ & $\begin{array}{c}t_{2} \\
(\mathrm{~mm})\end{array}$ & $\begin{array}{c}e \\
(\mathrm{~mm})\end{array}$ & $e / d_{0}$ & $\begin{array}{c}a \\
(\mathrm{~mm})\end{array}$ \\
\hline CHS-N-ER-0.25 & 140 & 114 & 89 & 4.0 & 3.0 & 2.0 & 35 & 0.25 & -20 \\
\hline CHS-N-ER-0.50 & 140 & 114 & 89 & 4.0 & 3.0 & 2.0 & 70 & 0.50 & 15 \\
\hline CHS-N-ER-0.75 & 140 & 114 & 89 & 4.0 & 3.0 & 2.0 & 105 & 0.75 & 50 \\
\hline CHS-N-ER-1.00 & 140 & 114 & 89 & 4.0 & 3.0 & 2.0 & 140 & 1.00 & 85 \\
\hline
\end{tabular}

Table 2 Basic material mechanical properties

\begin{tabular}{|c|c|c|c|c|c|}
\hline $\begin{array}{c}\text { Members } \\
(\mathrm{mm})\end{array}$ & $\begin{array}{c}E \\
(\mathrm{GPa})\end{array}$ & $\begin{array}{c}f_{\mathrm{y}} \\
(\mathrm{MPa})\end{array}$ & $\begin{array}{c}f_{\mathrm{u}} \\
(\mathrm{MPa})\end{array}$ & $f_{\mathrm{y}} / f_{\mathrm{u}}$ & $\begin{array}{c}\varepsilon_{\mathrm{f}} \\
(\%)\end{array}$ \\
\hline $\mathrm{CHS} 140 \times 4$ & 214 & 331 & 418 & 0.792 & 25.28 \\
\hline $\mathrm{CHS} 114 \times 3$ & 208 & 310 & 422 & 0.735 & 26.96 \\
\hline $\mathrm{CHS} 89 \times 2$ & 197 & 321 & 405 & 0.793 & 23.28 \\
\hline
\end{tabular}

Table 3 Parametric study results

\begin{tabular}{|c|c|c|c|c|c|c|c|}
\hline \multicolumn{4}{|c|}{ Parameters } & \multicolumn{2}{|c|}{$\begin{array}{c}\text { Chord and vertical brace } \\
\text { intersection }\end{array}$} & \multicolumn{2}{|c|}{$\begin{array}{c}\text { Chord and inclined brace } \\
\text { intersection }\end{array}$} \\
\hline & & & & Near vertical brace & Near chord & Near inclined brace & Near chord \\
\hline$\varepsilon$ & $2 \gamma$ & $\beta$ & $\tau$ & SCF1 & SCF2 & SCF3 & SCF4 \\
\hline 0.3 & 30 & 0.3 & 0.3 & 1.706 & 1.661 & 1.244 & 0.707 \\
\hline 0.3 & 30 & 0.3 & 0.5 & 2.306 & 2.631 & 1.690 & 1.339 \\
\hline 0.3 & 30 & 0.3 & 0.7 & 2.738 & 3.561 & 2.068 & 2.039 \\
\hline 0.3 & 30 & 0.3 & 0.9 & 3.424 & 4.465 & 2.405 & 2.791 \\
\hline 0.3 & 30 & 0.4 & 0.3 & 2.083 & 1.743 & 1.111 & 0.742 \\
\hline 0.3 & 30 & 0.4 & 0.5 & 2.126 & 2.761 & 1.509 & 1.405 \\
\hline 0.3 & 30 & 0.4 & 0.7 & 2.575 & 3.737 & 1.846 & 2.140 \\
\hline 0.3 & 30 & 0.4 & 0.9 & 3.484 & 4.686 & 2.147 & 2.930 \\
\hline
\end{tabular}




\begin{tabular}{|c|c|c|c|c|c|c|c|}
\hline 0.3 & 30 & 0.5 & 0.3 & 1.795 & 1.790 & 1.000 & 0.762 \\
\hline 0.3 & 30 & 0.5 & 0.5 & 2.168 & 2.835 & 1.359 & 1.443 \\
\hline 0.3 & 30 & 0.5 & 0.7 & 2.496 & 3.837 & 1.663 & 2.197 \\
\hline 0.3 & 30 & 0.5 & 0.9 & 3.275 & 4.811 & 1.934 & 3.009 \\
\hline 0.3 & 30 & 0.6 & 0.3 & 1.517 & 1.801 & 0.906 & 0.767 \\
\hline 0.3 & 30 & 0.6 & 0.5 & 2.008 & 2.852 & 1.230 & 1.452 \\
\hline 0.3 & 30 & 0.6 & 0.7 & 2.359 & 3.860 & 1.506 & 2.211 \\
\hline 0.3 & 30 & 0.6 & 0.9 & 4.078 & 4.840 & 1.751 & 3.027 \\
\hline 0.3 & 35 & 0.3 & 0.3 & 2.448 & 1.938 & 1.429 & 1.056 \\
\hline 0.3 & 35 & 0.3 & 0.5 & 3.168 & 3.069 & 1.942 & 1.999 \\
\hline 0.3 & 35 & 0.3 & 0.7 & 3.313 & 4.154 & 2.376 & 3.044 \\
\hline 0.3 & 35 & 0.3 & 0.9 & 3.791 & 5.209 & 2.763 & 4.168 \\
\hline 0.3 & 35 & 0.4 & 0.3 & 2.173 & 2.034 & 1.276 & 1.108 \\
\hline 0.3 & 35 & 0.4 & 0.5 & 2.846 & 3.221 & 1.733 & 2.098 \\
\hline 0.3 & 35 & 0.4 & 0.7 & 2.938 & 4.360 & 2.121 & 3.195 \\
\hline 0.3 & 35 & 0.4 & 0.9 & 3.594 & 5.467 & 2.466 & 4.375 \\
\hline 0.3 & 35 & 0.5 & 0.3 & 2.017 & 2.088 & 1.149 & 1.138 \\
\hline 0.3 & 35 & 0.5 & 0.5 & 2.488 & 3.307 & 1.561 & 2.154 \\
\hline 0.3 & 35 & 0.5 & 0.7 & 2.623 & 4.477 & 1.911 & 3.281 \\
\hline 0.3 & 35 & 0.5 & 0.9 & 2.535 & 5.613 & 2.222 & 4.492 \\
\hline 0.3 & 35 & 0.6 & 0.3 & 2.095 & 2.101 & 1.040 & 1.145 \\
\hline 0.3 & 35 & 0.6 & 0.5 & 3.607 & 3.327 & 1.413 & 2.168 \\
\hline 0.3 & 35 & 0.6 & 0.7 & 4.388 & 4.504 & 1.730 & 3.301 \\
\hline 0.3 & 35 & 0.6 & 0.9 & 6.163 & 5.647 & 2.011 & 4.519 \\
\hline 0.3 & 40 & 0.3 & 0.3 & 2.321 & 2.215 & 1.612 & 1.494 \\
\hline 0.3 & 40 & 0.3 & 0.5 & 2.955 & 3.507 & 2.190 & 2.829 \\
\hline 0.3 & 40 & 0.3 & 0.7 & 3.319 & 4.748 & 2.679 & 4.308 \\
\hline 0.3 & 40 & 0.3 & 0.9 & 4.248 & 5.953 & 3.115 & 5.897 \\
\hline 0.3 & 40 & 0.4 & 0.3 & 2.148 & 2.325 & 1.439 & 1.568 \\
\hline
\end{tabular}




\begin{tabular}{|c|c|c|c|c|c|c|c|}
\hline 0.3 & 40 & 0.4 & 0.5 & 2.636 & 3.681 & 1.955 & 2.969 \\
\hline 0.3 & 40 & 0.4 & 0.7 & 3.127 & 4.983 & 2.392 & 4.522 \\
\hline 0.3 & 40 & 0.4 & 0.9 & 2.912 & 6.248 & 2.781 & 6.190 \\
\hline 0.3 & 40 & 0.5 & 0.3 & 1.913 & 2.387 & 1.296 & 1.610 \\
\hline 0.3 & 40 & 0.5 & 0.5 & 3.507 & 3.780 & 1.761 & 3.049 \\
\hline 0.3 & 40 & 0.5 & 0.7 & 4.097 & 5.116 & 2.155 & 4.643 \\
\hline 0.3 & 40 & 0.5 & 0.9 & 4.786 & 6.415 & 2.505 & 6.356 \\
\hline 0.3 & 40 & 0.6 & 0.3 & 2.287 & 2.401 & 1.173 & 1.620 \\
\hline 0.3 & 40 & 0.6 & 0.5 & 4.263 & 3.802 & 1.594 & 3.067 \\
\hline 0.3 & 40 & 0.6 & 0.7 & 5.937 & 5.147 & 1.950 & 4.671 \\
\hline 0.3 & 40 & 0.6 & 0.9 & 7.303 & 6.453 & 2.268 & 6.395 \\
\hline 0.3 & 45 & 0.3 & 0.3 & 2.946 & 2.492 & 1.792 & 2.029 \\
\hline 0.3 & 45 & 0.3 & 0.5 & 3.607 & 3.946 & 2.434 & 3.842 \\
\hline 0.3 & 45 & 0.3 & 0.7 & 4.220 & 5.341 & 2.979 & 5.851 \\
\hline 0.3 & 45 & 0.3 & 0.9 & 4.793 & 6.697 & 3.464 & 8.011 \\
\hline 0.3 & 45 & 0.4 & 0.3 & 2.447 & 2.615 & 1.600 & 2.130 \\
\hline 0.3 & 45 & 0.4 & 0.5 & 3.028 & 4.141 & 2.173 & 4.033 \\
\hline 0.3 & 45 & 0.4 & 0.7 & 3.545 & 5.606 & 2.660 & 6.142 \\
\hline 0.3 & 45 & 0.4 & 0.9 & 5.634 & 7.029 & 3.092 & 8.408 \\
\hline 0.3 & 45 & 0.5 & 0.3 & 2.111 & 2.685 & 1.441 & 2.187 \\
\hline 0.3 & 45 & 0.5 & 0.5 & 2.542 & 4.252 & 1.958 & 4.141 \\
\hline 0.3 & 45 & 0.5 & 0.7 & 2.677 & 5.756 & 2.396 & 6.306 \\
\hline 0.3 & 45 & 0.5 & 0.9 & 5.647 & 7.217 & 2.785 & 8.634 \\
\hline 0.3 & 45 & 0.6 & 0.3 & 1.758 & 2.701 & 1.304 & 2.200 \\
\hline 0.3 & 45 & 0.6 & 0.5 & 4.177 & 4.277 & 1.772 & 4.166 \\
\hline 0.3 & 45 & 0.6 & 0.7 & 7.372 & 5.790 & 2.169 & 6.345 \\
\hline 0.3 & 45 & 0.6 & 0.9 & 6.106 & 7.260 & 2.521 & 8.686 \\
\hline 0.5 & 30 & 0.3 & 0.3 & 1.759 & 1.926 & 1.140 & 0.632 \\
\hline 0.5 & 30 & 0.3 & 0.5 & 2.486 & 3.051 & 1.550 & 1.197 \\
\hline
\end{tabular}




\begin{tabular}{|c|c|c|c|c|c|c|c|}
\hline 0.5 & 30 & 0.3 & 0.7 & 2.946 & 4.130 & 1.896 & 1.822 \\
\hline 0.5 & 30 & 0.3 & 0.9 & 3.662 & 5.178 & 2.205 & 2.495 \\
\hline 0.5 & 30 & 0.4 & 0.3 & 1.813 & 2.022 & 1.018 & 0.663 \\
\hline 0.5 & 30 & 0.4 & 0.5 & 2.288 & 3.202 & 1.383 & 1.256 \\
\hline 0.5 & 30 & 0.4 & 0.7 & 2.791 & 4.334 & 1.693 & 1.913 \\
\hline 0.5 & 30 & 0.4 & 0.9 & 3.852 & 5.434 & 1.968 & 2.619 \\
\hline 0.5 & 30 & 0.5 & 0.3 & 1.951 & 2.076 & 0.917 & 0.681 \\
\hline 0.5 & 30 & 0.5 & 0.5 & 2.322 & 3.287 & 1.246 & 1.290 \\
\hline 0.5 & 30 & 0.5 & 0.7 & 2.647 & 4.450 & 1.525 & 1.964 \\
\hline 0.5 & 30 & 0.5 & 0.9 & 3.726 & 5.579 & 1.773 & 2.689 \\
\hline 0.5 & 30 & 0.6 & 0.3 & 1.604 & 2.088 & 0.830 & 0.685 \\
\hline 0.5 & 30 & 0.6 & 0.5 & 2.196 & 3.307 & 1.128 & 1.297 \\
\hline 0.5 & 30 & 0.6 & 0.7 & 2.682 & 4.477 & 1.380 & 1.976 \\
\hline 0.5 & 30 & 0.6 & 0.9 & 3.310 & 5.613 & 1.605 & 2.705 \\
\hline 0.5 & 35 & 0.3 & 0.3 & 2.656 & 2.247 & 1.310 & 0.943 \\
\hline 0.5 & 35 & 0.3 & 0.5 & 3.376 & 3.559 & 1.780 & 1.786 \\
\hline 0.5 & 35 & 0.3 & 0.7 & 3.786 & 4.818 & 2.178 & 2.720 \\
\hline 0.5 & 35 & 0.3 & 0.9 & 4.283 & 6.041 & 2.533 & 3.725 \\
\hline 0.5 & 35 & 0.4 & 0.3 & 2.265 & 2.359 & 1.170 & 0.990 \\
\hline 0.5 & 35 & 0.4 & 0.5 & 3.222 & 3.735 & 1.589 & 1.875 \\
\hline 0.5 & 35 & 0.4 & 0.7 & 3.411 & 5.057 & 1.945 & 2.856 \\
\hline 0.5 & 35 & 0.4 & 0.9 & 4.264 & 6.340 & 2.261 & 3.910 \\
\hline 0.5 & 35 & 0.5 & 0.3 & 2.164 & 2.422 & 1.054 & 1.017 \\
\hline 0.5 & 35 & 0.5 & 0.5 & 2.896 & 3.835 & 1.431 & 1.925 \\
\hline 0.5 & 35 & 0.5 & 0.7 & 3.517 & 5.192 & 1.752 & 2.932 \\
\hline 0.5 & 35 & 0.5 & 0.9 & 3.210 & 6.509 & 2.037 & 4.014 \\
\hline 0.5 & 35 & 0.6 & 0.3 & 1.681 & 2.436 & 0.954 & 1.023 \\
\hline 0.5 & 35 & 0.6 & 0.5 & 2.229 & 3.858 & 1.296 & 1.937 \\
\hline 0.5 & 35 & 0.6 & 0.7 & 2.351 & 5.223 & 1.586 & 2.950 \\
\hline
\end{tabular}




\begin{tabular}{|c|c|c|c|c|c|c|c|}
\hline 0.5 & 35 & 0.6 & 0.9 & 2.432 & 6.548 & 1.844 & 4.039 \\
\hline 0.5 & 40 & 0.3 & 0.3 & 2.845 & 2.568 & 1.478 & 1.335 \\
\hline 0.5 & 40 & 0.3 & 0.5 & 3.849 & 4.067 & 2.007 & 2.528 \\
\hline 0.5 & 40 & 0.3 & 0.7 & 4.316 & 5.506 & 2.457 & 3.850 \\
\hline 0.5 & 40 & 0.3 & 0.9 & 4.997 & 6.903 & 2.856 & 5.271 \\
\hline 0.5 & 40 & 0.4 & 0.3 & 2.576 & 2.696 & 1.319 & 1.401 \\
\hline 0.5 & 40 & 0.4 & 0.5 & 3.122 & 4.269 & 1.792 & 2.653 \\
\hline 0.5 & 40 & 0.4 & 0.7 & 3.481 & 5.779 & 2.193 & 4.041 \\
\hline 0.5 & 40 & 0.4 & 0.9 & 4.471 & 7.246 & 2.550 & 5.532 \\
\hline 0.5 & 40 & 0.5 & 0.3 & 2.212 & 2.768 & 1.188 & 1.439 \\
\hline 0.5 & 40 & 0.5 & 0.5 & 2.836 & 4.383 & 1.614 & 2.725 \\
\hline 0.5 & 40 & 0.5 & 0.7 & 3.143 & 5.933 & 1.975 & 4.149 \\
\hline 0.5 & 40 & 0.5 & 0.9 & 3.505 & 7.439 & 2.297 & 5.680 \\
\hline 0.5 & 40 & 0.6 & 0.3 & 1.879 & 2.784 & 1.076 & 1.448 \\
\hline 0.5 & 40 & 0.6 & 0.5 & 2.215 & 4.409 & 1.461 & 2.741 \\
\hline 0.5 & 40 & 0.6 & 0.7 & 2.892 & 5.969 & 1.788 & 4.174 \\
\hline 0.5 & 40 & 0.6 & 0.9 & 3.239 & 7.484 & 2.079 & 5.715 \\
\hline 0.5 & 45 & 0.3 & 0.3 & 3.152 & 2.889 & 1.643 & 1.813 \\
\hline 0.5 & 45 & 0.3 & 0.5 & 4.348 & 4.576 & 2.232 & 3.434 \\
\hline 0.5 & 45 & 0.3 & 0.7 & 4.303 & 6.194 & 2.731 & 5.229 \\
\hline 0.5 & 45 & 0.3 & 0.9 & 4.997 & 7.766 & 3.176 & 7.159 \\
\hline 0.5 & 45 & 0.4 & 0.3 & 2.871 & 3.033 & 1.467 & 1.903 \\
\hline 0.5 & 45 & 0.4 & 0.5 & 3.645 & 4.803 & 1.993 & 3.604 \\
\hline 0.5 & 45 & 0.4 & 0.7 & 3.635 & 6.501 & 2.438 & 5.489 \\
\hline 0.5 & 45 & 0.4 & 0.9 & 4.028 & 8.151 & 2.835 & 7.515 \\
\hline 0.5 & 45 & 0.5 & 0.3 & 2.165 & 3.114 & 1.321 & 1.954 \\
\hline 0.5 & 45 & 0.5 & 0.5 & 2.661 & 4.931 & 1.795 & 3.701 \\
\hline 0.5 & 45 & 0.5 & 0.7 & 2.925 & 6.675 & 2.196 & 5.636 \\
\hline 0.5 & 45 & 0.5 & 0.9 & 3.682 & 8.369 & 2.554 & 7.716 \\
\hline
\end{tabular}




\begin{tabular}{|c|c|c|c|c|c|c|c|}
\hline 0.5 & 45 & 0.6 & 0.3 & 1.768 & 3.132 & 1.196 & 1.966 \\
\hline 0.5 & 45 & 0.6 & 0.5 & 3.909 & 4.960 & 1.625 & 3.723 \\
\hline 0.5 & 45 & 0.6 & 0.7 & 5.206 & 6.715 & 1.988 & 5.670 \\
\hline 0.5 & 45 & 0.6 & 0.9 & 5.287 & 8.419 & 2.312 & 7.763 \\
\hline 0.7 & 30 & 0.3 & 0.3 & 2.198 & 2.124 & 1.077 & 0.587 \\
\hline 0.7 & 30 & 0.3 & 0.5 & 2.631 & 3.363 & 1.463 & 1.111 \\
\hline 0.7 & 30 & 0.3 & 0.7 & 2.922 & 4.553 & 1.791 & 1.692 \\
\hline 0.7 & 30 & 0.3 & 0.9 & 3.512 & 5.708 & 2.082 & 2.317 \\
\hline 0.7 & 30 & 0.4 & 0.3 & 1.533 & 2.229 & 0.962 & 0.616 \\
\hline 0.7 & 30 & 0.4 & 0.5 & 2.399 & 3.530 & 1.306 & 1.166 \\
\hline 0.7 & 30 & 0.4 & 0.7 & 2.970 & 4.778 & 1.599 & 1.776 \\
\hline 0.7 & 30 & 0.4 & 0.9 & 4.134 & 5.991 & 1.859 & 2.432 \\
\hline 0.7 & 30 & 0.5 & 0.3 & 2.040 & 2.288 & 0.866 & 0.632 \\
\hline 0.7 & 30 & 0.5 & 0.5 & 2.639 & 3.624 & 1.177 & 1.198 \\
\hline 0.7 & 30 & 0.5 & 0.7 & 2.995 & 4.906 & 1.440 & 1.824 \\
\hline 0.7 & 30 & 0.5 & 0.9 & 4.104 & 6.151 & 1.674 & 2.497 \\
\hline 0.7 & 30 & 0.6 & 0.3 & 1.689 & 2.302 & 0.784 & 0.636 \\
\hline 0.7 & 30 & 0.6 & 0.5 & 2.383 & 3.646 & 1.065 & 1.205 \\
\hline 0.7 & 30 & 0.6 & 0.7 & 2.989 & 4.935 & 1.304 & 1.835 \\
\hline 0.7 & 30 & 0.6 & 0.9 & 2.843 & 6.188 & 1.516 & 2.512 \\
\hline 0.7 & 35 & 0.3 & 0.3 & 3.206 & 2.478 & 1.237 & 0.876 \\
\hline 0.7 & 35 & 0.3 & 0.5 & 4.187 & 3.924 & 1.681 & 1.659 \\
\hline 0.7 & 35 & 0.3 & 0.7 & 5.127 & 5.312 & 2.057 & 2.526 \\
\hline 0.7 & 35 & 0.3 & 0.9 & 5.755 & 6.660 & 2.392 & 3.459 \\
\hline 0.7 & 35 & 0.4 & 0.3 & 2.721 & 2.600 & 1.105 & 0.920 \\
\hline 0.7 & 35 & 0.4 & 0.5 & 3.543 & 4.118 & 1.501 & 1.741 \\
\hline 0.7 & 35 & 0.4 & 0.7 & 4.375 & 5.575 & 1.837 & 2.652 \\
\hline 0.7 & 35 & 0.4 & 0.9 & 5.443 & 6.990 & 2.136 & 3.631 \\
\hline 0.7 & 35 & 0.5 & 0.3 & 2.419 & 2.670 & 0.995 & 0.944 \\
\hline
\end{tabular}




\begin{tabular}{|c|c|c|c|c|c|c|c|}
\hline 0.7 & 35 & 0.5 & 0.5 & 3.218 & 4.228 & 1.352 & 1.788 \\
\hline 0.7 & 35 & 0.5 & 0.7 & 3.470 & 5.724 & 1.654 & 2.723 \\
\hline 0.7 & 35 & 0.5 & 0.9 & 3.767 & 7.176 & 1.924 & 3.728 \\
\hline 0.7 & 35 & 0.6 & 0.3 & 1.951 & 2.686 & 0.901 & 0.950 \\
\hline 0.7 & 35 & 0.6 & 0.5 & 2.385 & 4.254 & 1.224 & 1.799 \\
\hline 0.7 & 35 & 0.6 & 0.7 & 2.765 & 5.758 & 1.498 & 2.739 \\
\hline 0.7 & 35 & 0.6 & 0.9 & 2.902 & 7.219 & 1.741 & 3.751 \\
\hline 0.7 & 40 & 0.3 & 0.3 & 2.814 & 2.832 & 1.395 & 1.240 \\
\hline 0.7 & 40 & 0.3 & 0.5 & 3.702 & 4.484 & 1.896 & 2.348 \\
\hline 0.7 & 40 & 0.3 & 0.7 & 4.634 & 6.070 & 2.320 & 3.575 \\
\hline 0.7 & 40 & 0.3 & 0.9 & 5.512 & 7.611 & 2.698 & 4.895 \\
\hline 0.7 & 40 & 0.4 & 0.3 & 2.911 & 2.972 & 1.246 & 1.301 \\
\hline 0.7 & 40 & 0.4 & 0.5 & 3.765 & 4.707 & 1.693 & 2.464 \\
\hline 0.7 & 40 & 0.4 & 0.7 & 4.415 & 6.371 & 2.071 & 3.753 \\
\hline 0.7 & 40 & 0.4 & 0.9 & 5.212 & 7.988 & 2.408 & 5.138 \\
\hline 0.7 & 40 & 0.5 & 0.3 & 2.531 & 3.051 & 1.122 & 1.336 \\
\hline 0.7 & 40 & 0.5 & 0.5 & 3.275 & 4.832 & 1.525 & 2.530 \\
\hline 0.7 & 40 & 0.5 & 0.7 & 4.099 & 6.541 & 1.866 & 3.853 \\
\hline 0.7 & 40 & 0.5 & 0.9 & 4.410 & 8.202 & 2.169 & 5.275 \\
\hline 0.7 & 40 & 0.6 & 0.3 & 1.888 & 3.070 & 1.016 & 1.344 \\
\hline 0.7 & 40 & 0.6 & 0.5 & 2.671 & 4.861 & 1.380 & 2.546 \\
\hline 0.7 & 40 & 0.6 & 0.7 & 3.023 & 6.581 & 1.689 & 3.877 \\
\hline 0.7 & 40 & 0.6 & 0.9 & 3.563 & 8.251 & 1.964 & 5.307 \\
\hline 0.7 & 45 & 0.3 & 0.3 & 3.607 & 3.186 & 1.551 & 1.684 \\
\hline 0.7 & 45 & 0.3 & 0.5 & 4.338 & 5.045 & 2.108 & 3.189 \\
\hline 0.7 & 45 & 0.3 & 0.7 & 5.162 & 6.829 & 2.579 & 4.856 \\
\hline 0.7 & 45 & 0.3 & 0.9 & 5.897 & 8.562 & 2.999 & 6.648 \\
\hline 0.7 & 45 & 0.4 & 0.3 & 3.085 & 3.343 & 1.385 & 1.767 \\
\hline 0.7 & 45 & 0.4 & 0.5 & 3.982 & 5.295 & 1.882 & 3.347 \\
\hline
\end{tabular}




\begin{tabular}{|c|c|c|c|c|c|c|c|}
\hline 0.7 & 45 & 0.4 & 0.7 & 4.717 & 7.168 & 2.303 & 5.097 \\
\hline 0.7 & 45 & 0.4 & 0.9 & 5.271 & 8.987 & 2.678 & 6.978 \\
\hline 0.7 & 45 & 0.5 & 0.3 & 2.679 & 3.433 & 1.248 & 1.815 \\
\hline 0.7 & 45 & 0.5 & 0.5 & 3.475 & 5.436 & 1.695 & 3.437 \\
\hline 0.7 & 45 & 0.5 & 0.7 & 3.951 & 7.359 & 2.074 & 5.234 \\
\hline 0.7 & 45 & 0.5 & 0.9 & 4.796 & 9.227 & 2.412 & 7.165 \\
\hline 0.7 & 45 & 0.6 & 0.3 & 1.932 & 3.453 & 1.129 & 1.826 \\
\hline 0.7 & 45 & 0.6 & 0.5 & 2.565 & 5.469 & 1.534 & 3.458 \\
\hline 0.7 & 45 & 0.6 & 0.7 & 2.885 & 7.403 & 1.878 & 5.266 \\
\hline 0.7 & 45 & 0.6 & 0.9 & 3.246 & 9.282 & 2.183 & 7.209 \\
\hline 0.9 & 30 & 0.3 & 0.3 & 2.288 & 2.284 & 1.032 & 0.555 \\
\hline 0.9 & 30 & 0.3 & 0.5 & 2.726 & 3.618 & 1.402 & 1.051 \\
\hline 0.9 & 30 & 0.3 & 0.7 & 3.261 & 4.897 & 1.716 & 1.601 \\
\hline 0.9 & 30 & 0.3 & 0.9 & 4.179 & 6.140 & 1.995 & 2.192 \\
\hline 0.9 & 30 & 0.4 & 0.3 & 1.577 & 2.398 & 0.921 & 0.583 \\
\hline 0.9 & 30 & 0.4 & 0.5 & 2.488 & 3.797 & 1.252 & 1.104 \\
\hline 0.9 & 30 & 0.4 & 0.7 & 3.115 & 5.140 & 1.532 & 1.681 \\
\hline 0.9 & 30 & 0.4 & 0.9 & 4.352 & 6.444 & 1.781 & 2.301 \\
\hline 0.9 & 30 & 0.5 & 0.3 & 2.271 & 2.462 & 0.830 & 0.598 \\
\hline 0.9 & 30 & 0.5 & 0.5 & 2.733 & 3.898 & 1.128 & 1.133 \\
\hline 0.9 & 30 & 0.5 & 0.7 & 3.181 & 5.277 & 1.380 & 1.726 \\
\hline 0.9 & 30 & 0.5 & 0.9 & 4.410 & 6.616 & 1.604 & 2.363 \\
\hline 0.9 & 30 & 0.6 & 0.3 & 1.757 & 2.476 & 0.751 & 0.602 \\
\hline 0.9 & 30 & 0.6 & 0.5 & 2.550 & 3.922 & 1.021 & 1.140 \\
\hline 0.9 & 30 & 0.6 & 0.7 & 3.226 & 5.309 & 1.249 & 1.736 \\
\hline 0.9 & 30 & 0.6 & 0.9 & 3.235 & 6.656 & 1.452 & 2.377 \\
\hline 0.9 & 35 & 0.3 & 0.3 & 3.051 & 2.665 & 1.186 & 0.829 \\
\hline 0.9 & 35 & 0.3 & 0.5 & 4.301 & 4.220 & 1.611 & 1.570 \\
\hline 0.9 & 35 & 0.3 & 0.7 & 4.274 & 5.713 & 1.971 & 2.390 \\
\hline
\end{tabular}




\begin{tabular}{|c|c|c|c|c|c|c|c|}
\hline 0.9 & 35 & 0.3 & 0.9 & 6.033 & 7.163 & 2.292 & 3.273 \\
\hline 0.9 & 35 & 0.4 & 0.3 & 2.833 & 2.797 & 1.058 & 0.870 \\
\hline 0.9 & 35 & 0.4 & 0.5 & 3.712 & 4.430 & 1.438 & 1.648 \\
\hline 0.9 & 35 & 0.4 & 0.7 & 3.701 & 5.996 & 1.760 & 2.509 \\
\hline 0.9 & 35 & 0.4 & 0.9 & 5.768 & 7.518 & 2.046 & 3.435 \\
\hline 0.9 & 35 & 0.5 & 0.3 & 2.592 & 2.872 & 0.953 & 0.893 \\
\hline 0.9 & 35 & 0.5 & 0.5 & 3.567 & 4.548 & 1.295 & 1.692 \\
\hline 0.9 & 35 & 0.5 & 0.7 & 3.783 & 6.156 & 1.585 & 2.576 \\
\hline 0.9 & 35 & 0.5 & 0.9 & 4.488 & 7.719 & 1.843 & 3.527 \\
\hline 0.9 & 35 & 0.6 & 0.3 & 2.146 & 2.889 & 0.863 & 0.899 \\
\hline 0.9 & 35 & 0.6 & 0.5 & 2.766 & 4.575 & 1.173 & 1.702 \\
\hline 0.9 & 35 & 0.6 & 0.7 & 3.116 & 6.193 & 1.435 & 2.592 \\
\hline 0.9 & 35 & 0.6 & 0.9 & 3.441 & 7.765 & 1.668 & 3.549 \\
\hline 0.9 & 40 & 0.3 & 0.3 & 3.202 & 3.046 & 1.337 & 1.173 \\
\hline 0.9 & 40 & 0.3 & 0.5 & 3.563 & 4.823 & 1.817 & 2.221 \\
\hline 0.9 & 40 & 0.3 & 0.7 & 4.921 & 6.529 & 2.223 & 3.383 \\
\hline 0.9 & 40 & 0.3 & 0.9 & 5.575 & 8.186 & 2.585 & 4.631 \\
\hline 0.9 & 40 & 0.4 & 0.3 & 2.940 & 3.197 & 1.194 & 1.231 \\
\hline 0.9 & 40 & 0.4 & 0.5 & 3.722 & 5.062 & 1.622 & 2.332 \\
\hline 0.9 & 40 & 0.4 & 0.7 & 4.374 & 6.853 & 1.985 & 3.551 \\
\hline 0.9 & 40 & 0.4 & 0.9 & 4.828 & 8.592 & 2.308 & 4.861 \\
\hline 0.9 & 40 & 0.5 & 0.3 & 2.886 & 3.282 & 1.075 & 1.264 \\
\hline 0.9 & 40 & 0.5 & 0.5 & 3.369 & 5.198 & 1.461 & 2.394 \\
\hline 0.9 & 40 & 0.5 & 0.7 & 4.451 & 7.036 & 1.788 & 3.646 \\
\hline 0.9 & 40 & 0.5 & 0.9 & 4.488 & 8.822 & 2.078 & 4.991 \\
\hline 0.9 & 40 & 0.6 & 0.3 & 2.165 & 3.302 & 0.973 & 1.272 \\
\hline 0.9 & 40 & 0.6 & 0.5 & 2.632 & 5.229 & 1.322 & 2.409 \\
\hline 0.9 & 40 & 0.6 & 0.7 & 2.904 & 7.078 & 1.618 & 3.668 \\
\hline 0.9 & 40 & 0.6 & 0.9 & 3.995 & 8.875 & 1.882 & 5.022 \\
\hline
\end{tabular}




\begin{tabular}{|c|c|c|c|c|c|c|c|}
\hline 0.9 & 45 & 0.3 & 0.3 & 3.779 & 3.426 & 1.487 & 1.593 \\
\hline 0.9 & 45 & 0.3 & 0.5 & 4.509 & 5.426 & 2.020 & 3.017 \\
\hline 0.9 & 45 & 0.3 & 0.7 & 5.684 & 7.345 & 2.472 & 4.595 \\
\hline 0.9 & 45 & 0.3 & 0.9 & 6.566 & 9.210 & 2.874 & 6.291 \\
\hline 0.9 & 45 & 0.4 & 0.3 & 3.349 & 3.596 & 1.327 & 1.672 \\
\hline 0.9 & 45 & 0.4 & 0.5 & 4.293 & 5.695 & 1.803 & 3.167 \\
\hline 0.9 & 45 & 0.4 & 0.7 & 5.035 & 7.710 & 2.207 & 4.823 \\
\hline 0.9 & 45 & 0.4 & 0.9 & 5.796 & 9.666 & 2.566 & 6.603 \\
\hline 0.9 & 45 & 0.5 & 0.3 & 2.942 & 3.692 & 1.195 & 1.717 \\
\hline 0.9 & 45 & 0.5 & 0.5 & 3.871 & 5.847 & 1.624 & 3.252 \\
\hline 0.9 & 45 & 0.5 & 0.7 & 4.279 & 7.915 & 1.987 & 4.952 \\
\hline 0.9 & 45 & 0.5 & 0.9 & 4.889 & 9.924 & 2.311 & 6.780 \\
\hline 0.9 & 45 & 0.6 & 0.3 & 2.163 & 3.714 & 1.082 & 1.728 \\
\hline 0.9 & 45 & 0.6 & 0.5 & 2.883 & 5.882 & 1.470 & 3.272 \\
\hline 0.9 & 45 & 0.6 & 0.7 & 3.250 & 7.963 & 1.799 & 4.982 \\
\hline 0.9 & 45 & 0.6 & 0.9 & 3.547 & 9.984 & 2.092 & 6.821 \\
\hline
\end{tabular}

Remark:

SCF1 is the maximum SCF values of the chord and vertical brace intersection welding seam near the vertical brace intersecting line

SCF2 is the maximum SCF values of the chord and vertical brace intersection welding seam near the chord intersecting line

SCF3 is the maximum SCF values of the inclined brace and chord intersection welding seam near the inclined brace intersecting line

SCF4 is the maximum SCF values of the inclined brace and chord intersection welding seam near the chord intersecting line. 


\section{Table 4 Comparison of CIDECT formulae calculation with FEA results for positive large} eccentricity CHS N-joints

\begin{tabular}{|c|c|c|c|c|}
\hline \multirow{2}{*}{$\begin{array}{c}\text { A total of 256 } \\
\text { specimens }\end{array}$} & $\begin{array}{c}\text { Comparison } \\
\text { brace intersection } \\
\text { near the vertical } \\
\text { brace intersection }\end{array}$ & $\begin{array}{c}\text { Chord and } \\
\text { intersection near } \\
\text { the chord } \\
\text { intersection }\end{array}$ & $\begin{array}{c}\text { Chord and } \\
\text { inclined brace } \\
\text { intersection near } \\
\text { the inclined brace }\end{array}$ & $\begin{array}{c}\text { Chord and } \\
\text { inclined brace } \\
\text { intersection near } \\
\text { the chord } \\
\text { Max }\end{array}$ \\
\hline Min & 1.296 & 1.043 & 3.309 & intersection \\
\hline Mean & 0.300 & 0.177 & 0.520 & 7.124 \\
\hline COV & 0.123 & 0.503 & 1.588 & 0.153 \\
\hline
\end{tabular}

Table 5 Comparison of proposed formulae calculation with FEA results for positive large eccentricity CHS N-joints

\begin{tabular}{|c|c|c|c|c|}
\hline \multirow[b]{2}{*}{$\begin{array}{l}\text { A total of } 256 \\
\text { specimens }\end{array}$} & \multicolumn{4}{|c|}{ Comparison } \\
\hline & $\begin{array}{l}\text { Chord and vertical } \\
\text { brace intersection } \\
\text { near the vertical } \\
\text { brace intersection }\end{array}$ & $\begin{array}{l}\text { Chord and } \\
\text { vertical brace } \\
\text { intersection near } \\
\text { the chord } \\
\text { intersection }\end{array}$ & $\begin{array}{l}\text { Chord and } \\
\text { inclined brace } \\
\text { intersection near } \\
\text { the inclined brace } \\
\text { intersection }\end{array}$ & $\begin{array}{c}\text { Chord and } \\
\text { inclined brace } \\
\text { intersection near } \\
\text { the chord } \\
\text { intersection }\end{array}$ \\
\hline Max & 1.509 & 1.788 & 2.547 & 3.036 \\
\hline Min & 0.465 & 0.473 & 0.337 & 0.286 \\
\hline Mean & 1.027 & 1.048 & 1.084 & 1.087 \\
\hline $\mathrm{COV}$ & 0.027 & 0.051 & 0.097 & 0.172 \\
\hline
\end{tabular}




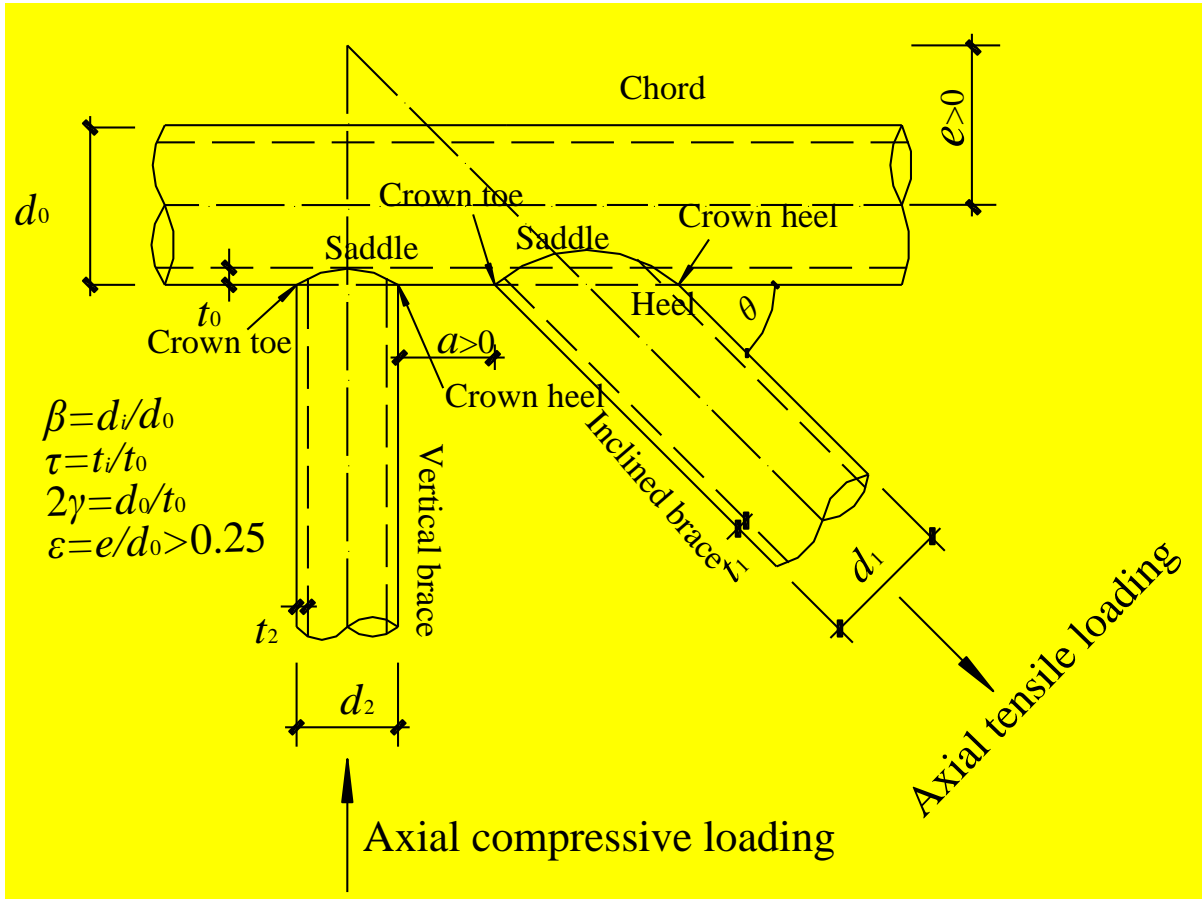

Fig. 1. Positive large eccentricity CHS N-joints under axial loading

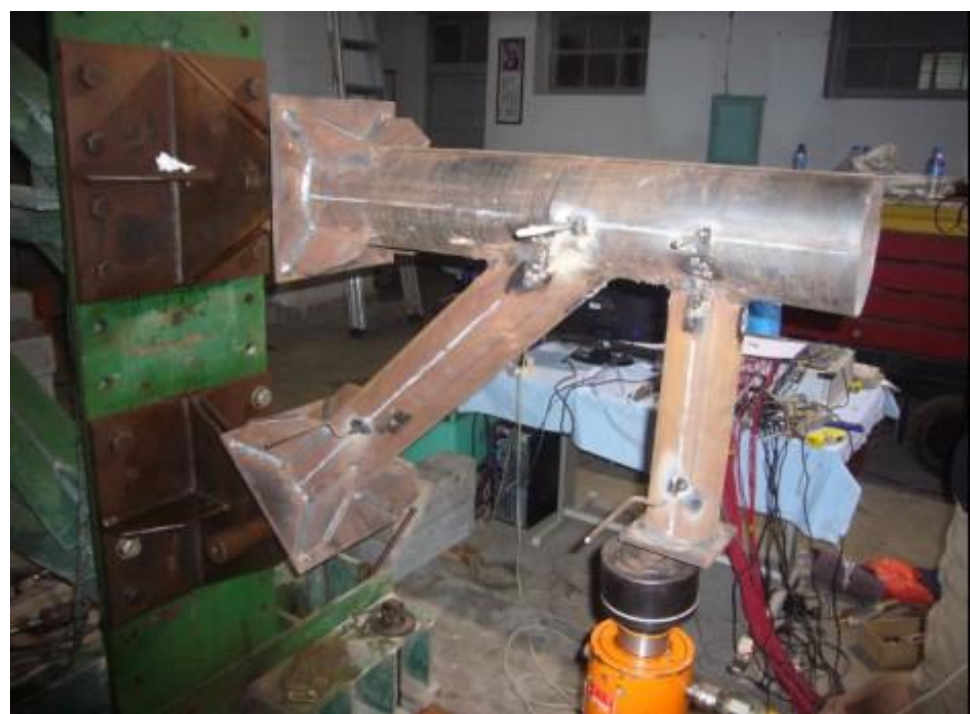

Fig. 2. Photo of positive large eccentricity $\mathrm{N}$-joints under axial loading 


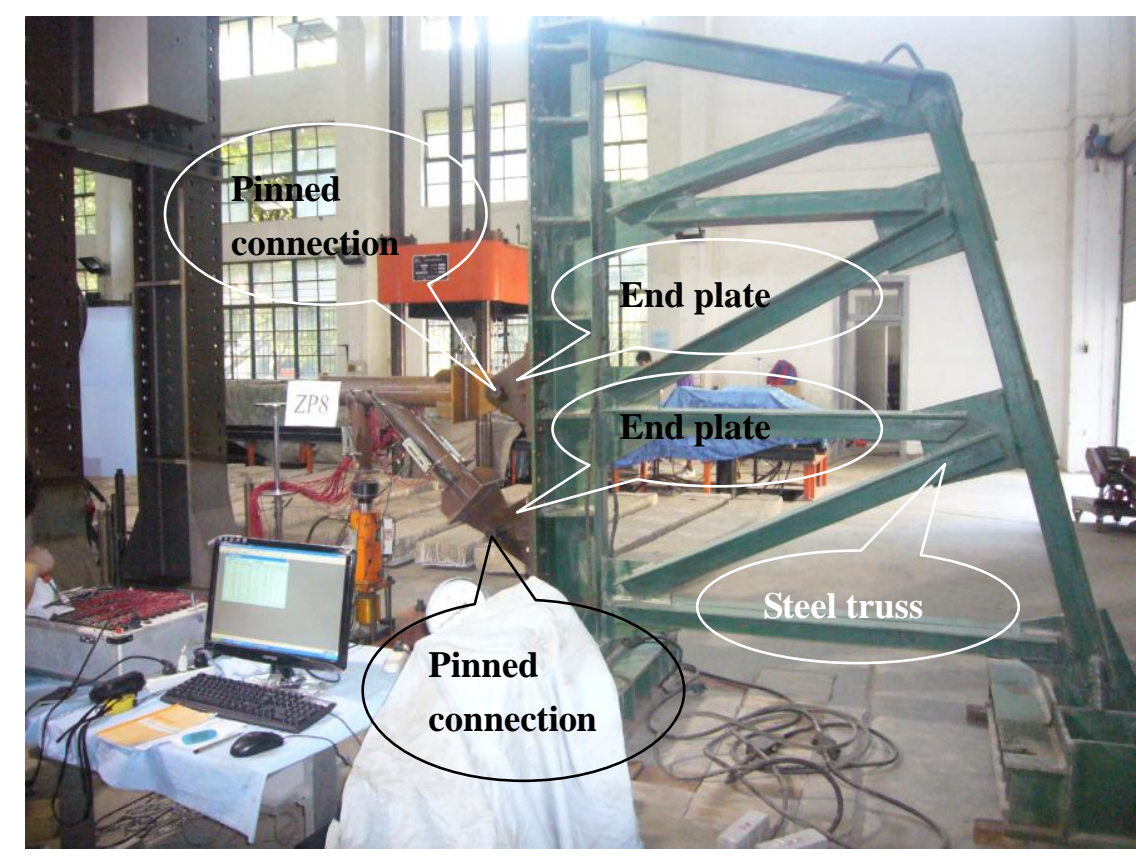

Fig. 3. Test rig 


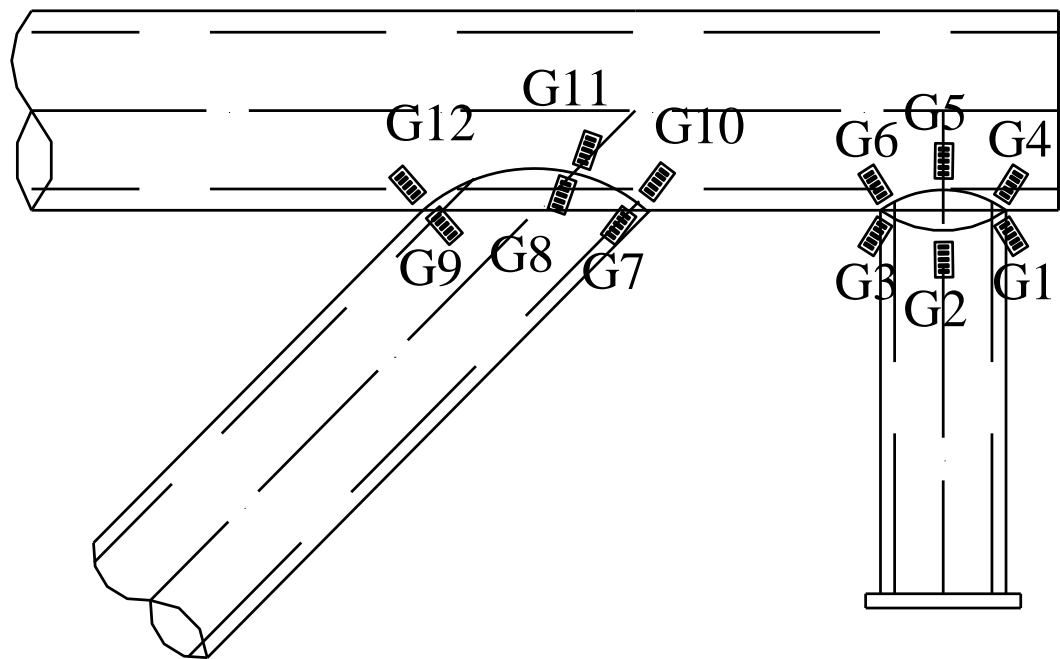

(a) Overview

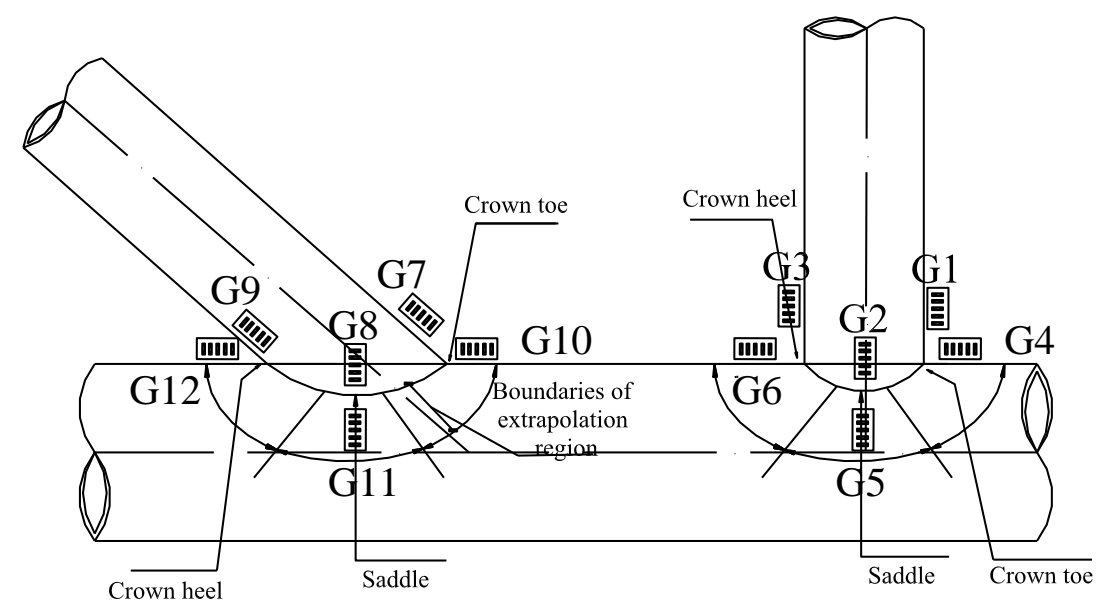

(b) Side view

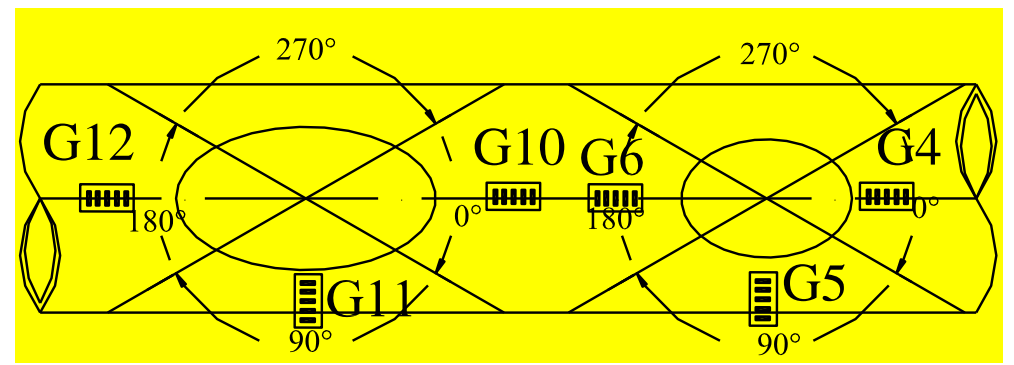

(c) Top view

Fig. 4. Gradient strain gauges at intersections of $\mathrm{N}$-joints 


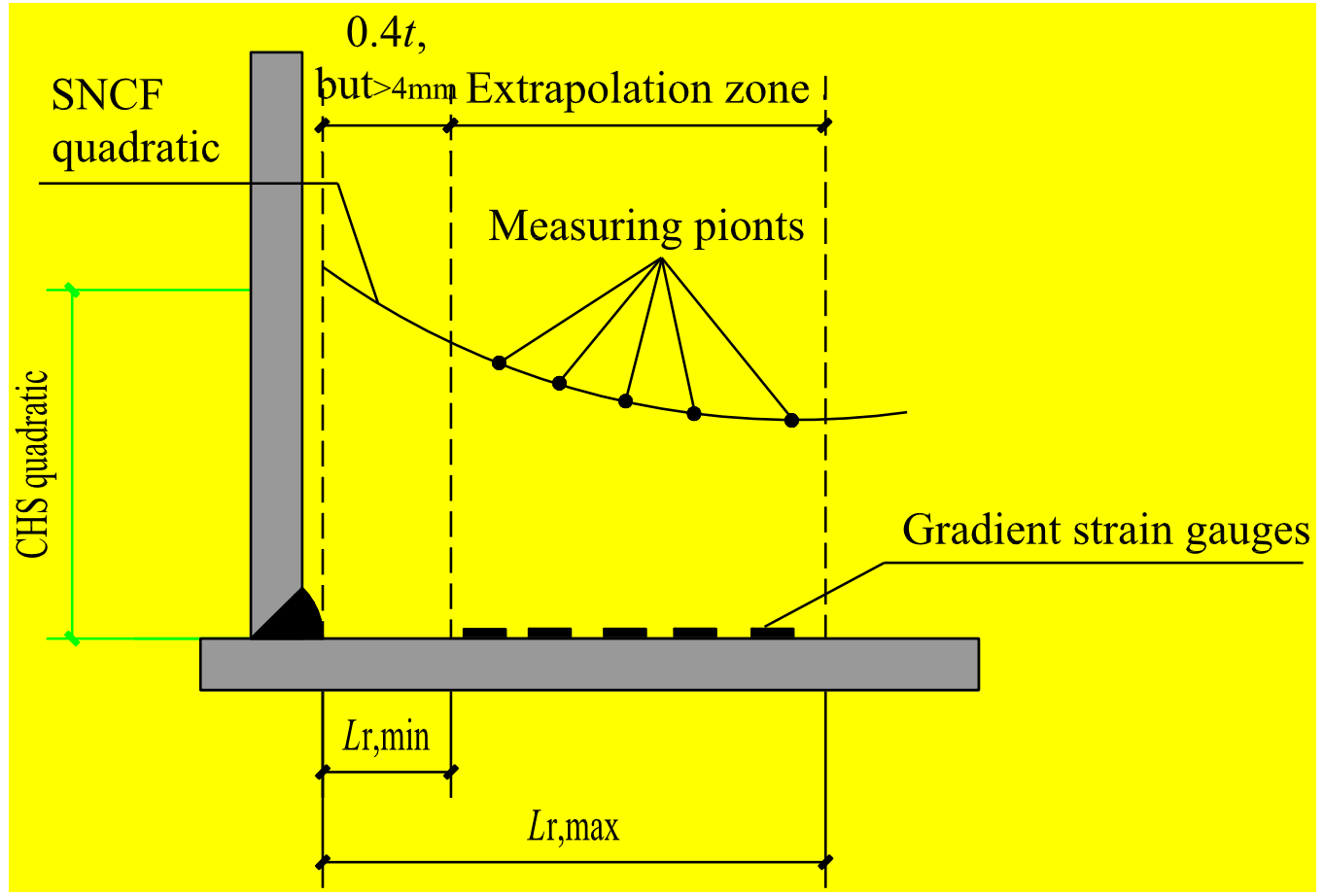

Fig. 5. Definition of extrapolation region of positive large eccentricity CHS N-joints 


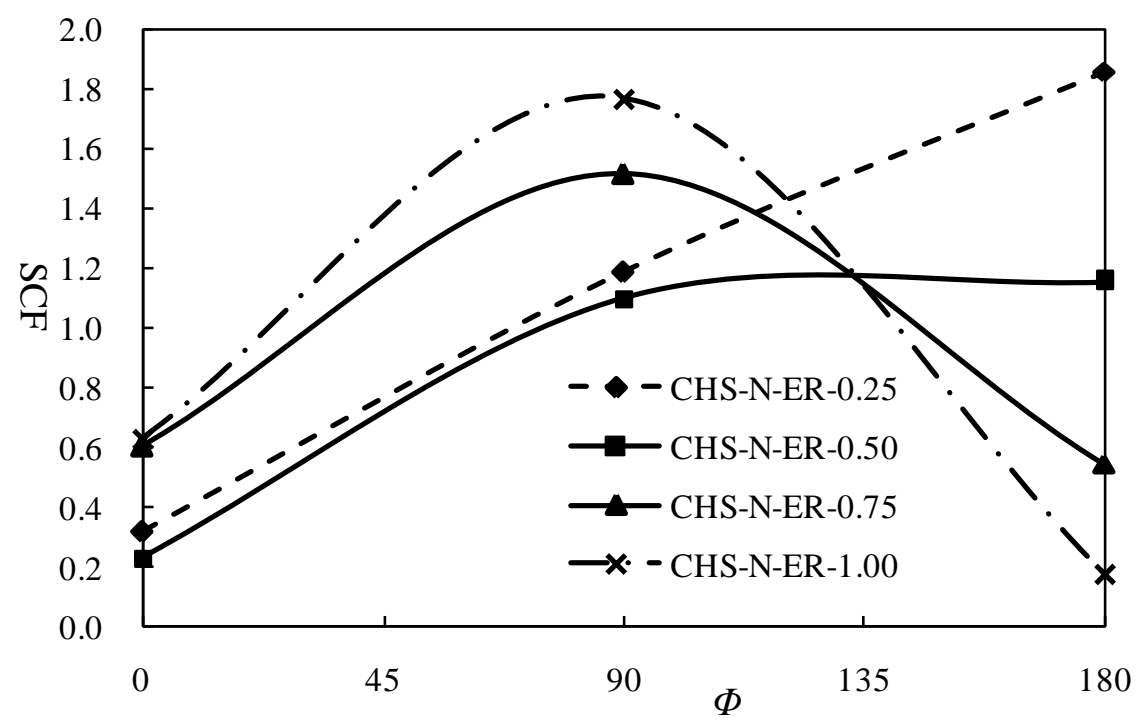

(a) Chord and vertical brace intersection welding seam near the vertical brace intersecting line

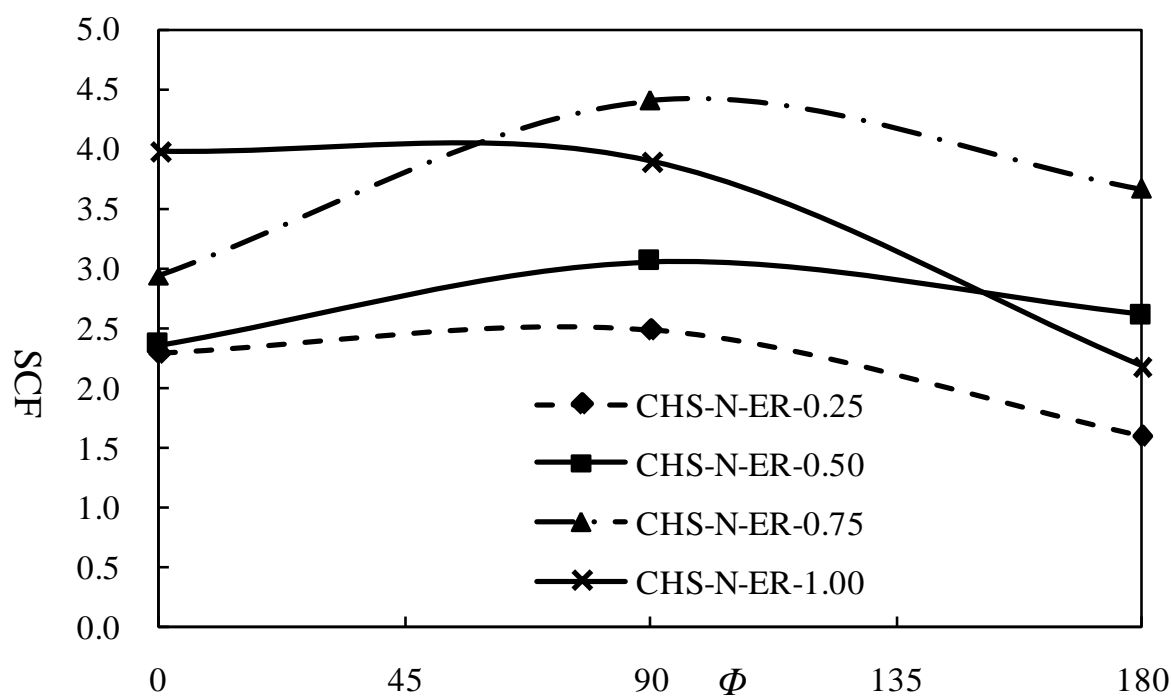

(b) Chord and vertical brace intersection welding seam near the chord intersecting line 


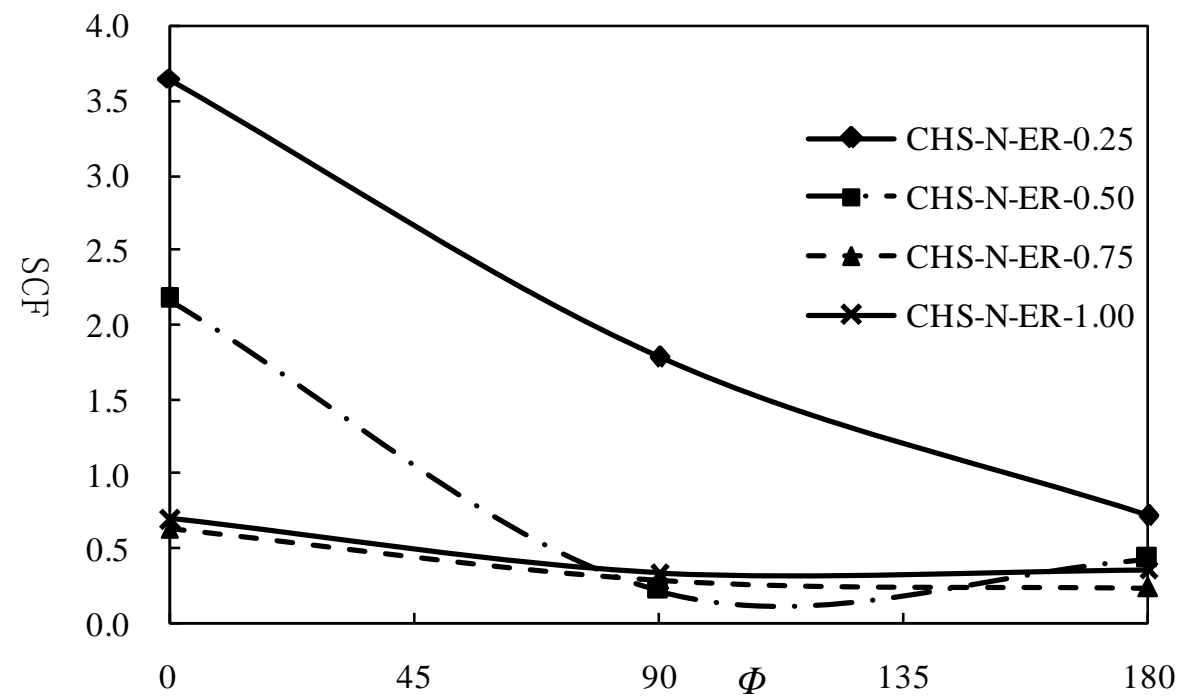

(c) Inclined brace and chord intersection welding seam near the inclined brace intersecting line

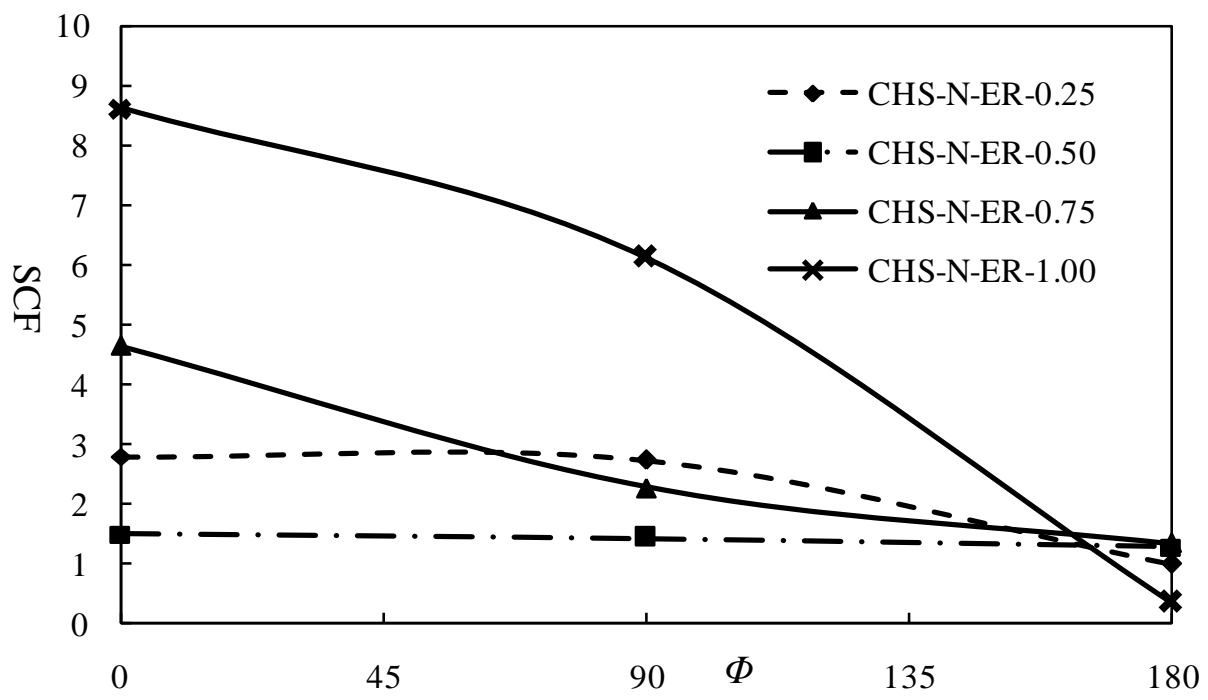

(d) Inclined brace and chord intersection welding seam near the chord intersecting line

Fig. 6. SCF of experimental joints 


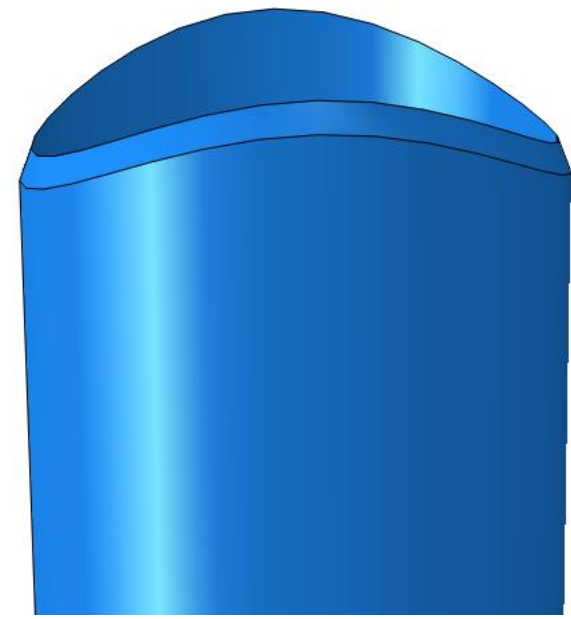

(a) Brace end

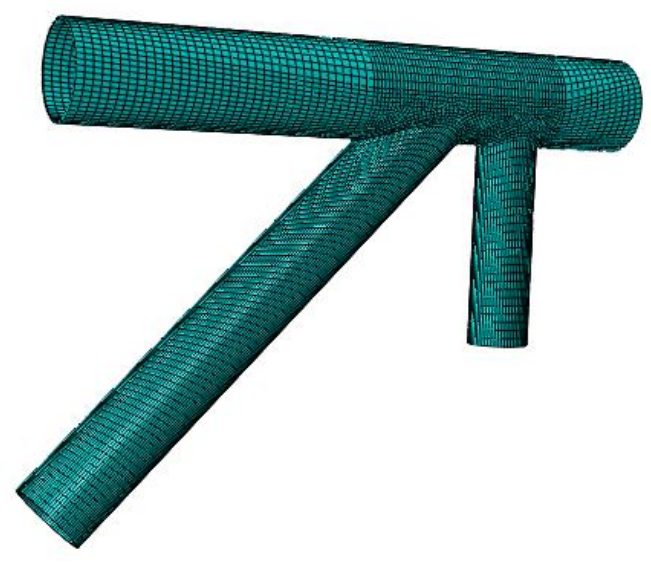

(c) Mesh of joint

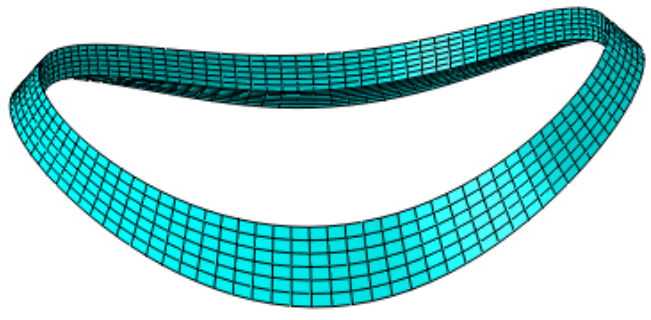

(e) Welding seam

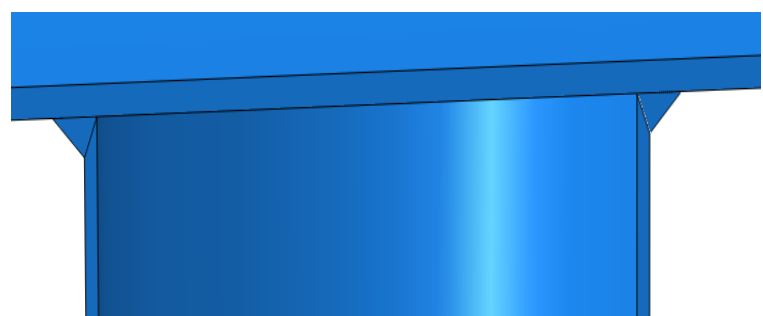

(b) Solid model of welding seams

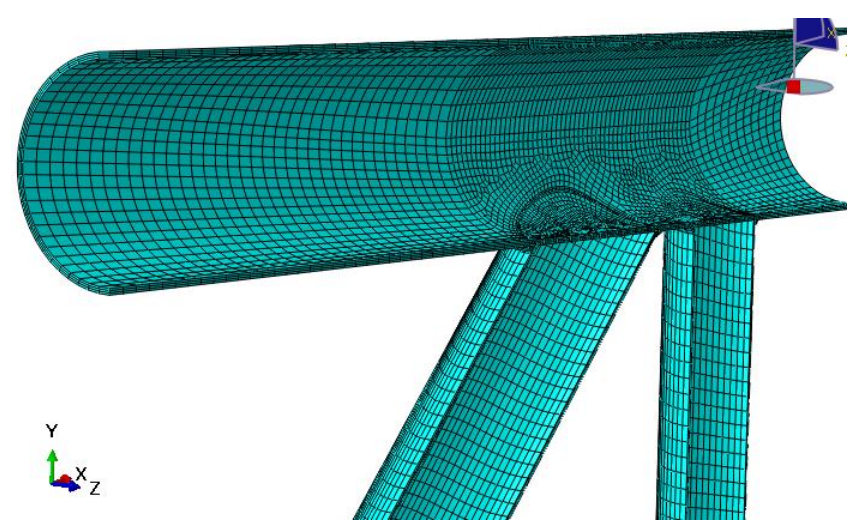

(d) Internal detail of joint

Fig. 7. Finite element model of CHS N-joints 


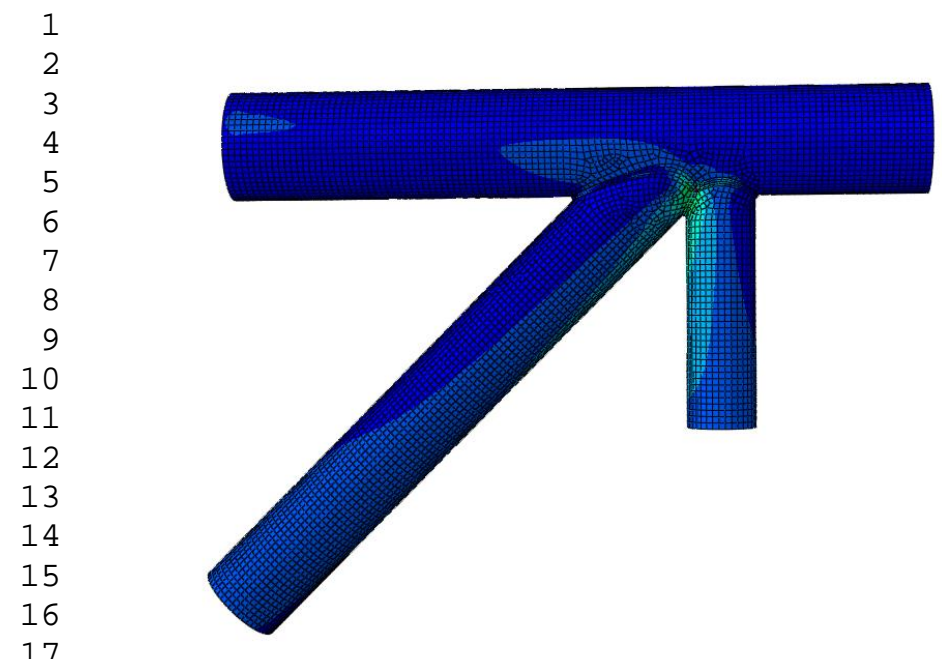

(a) CHS-N-ER-0.25

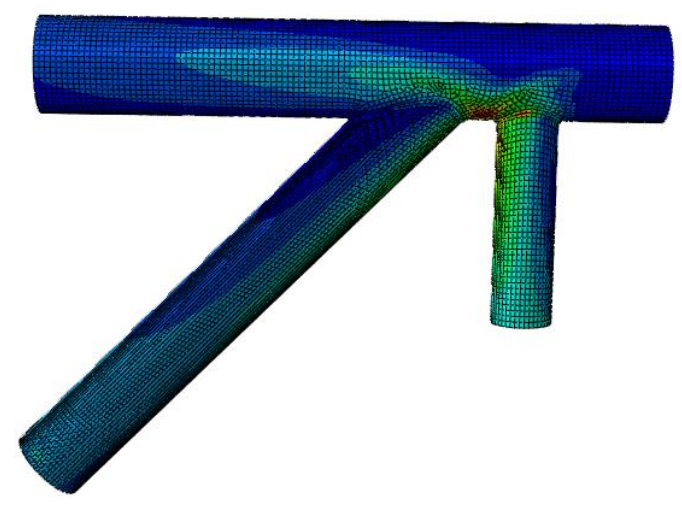

(c) CHS-N-ER-0.75

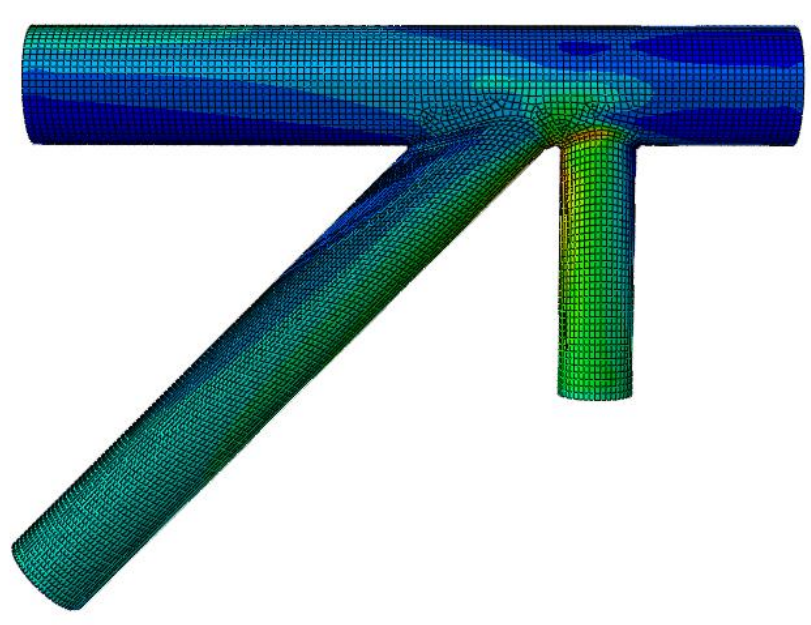

(b) CHS-N-ER-0.50

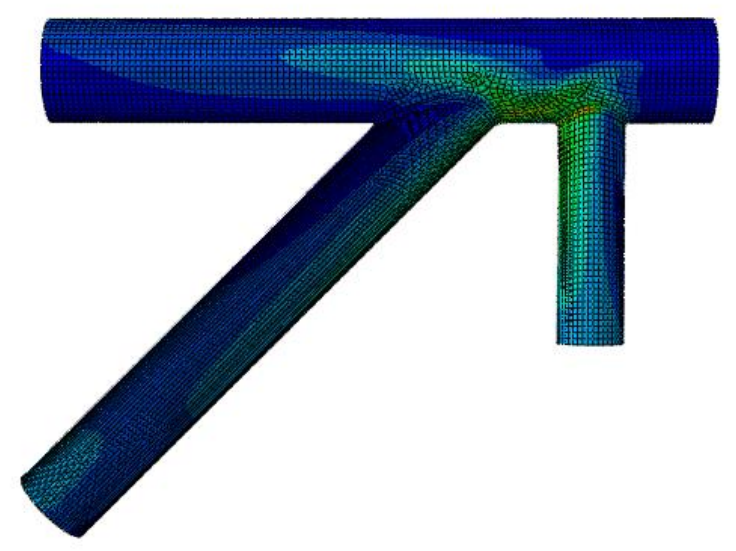

(d) CHS-N-ER-1.00

Fig. 8. Stress distribution of experimental $\mathrm{N}$-joints 
(a) Chord and vertical brace intersection welding seam near the vertical brace intersecting line
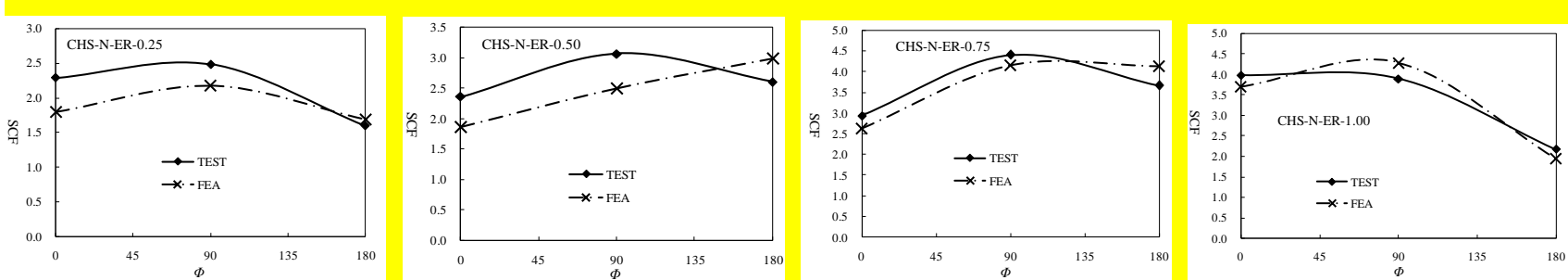

(b) Chord and vertical brace intersection welding seam near the chord intersecting line
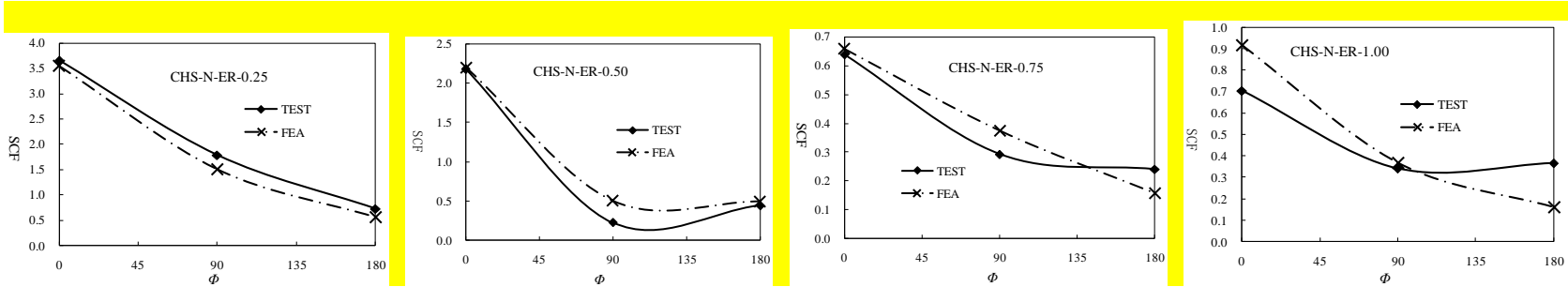

(c) Chord and inclined brace intersection welding seam near the inclined brace intersecting line
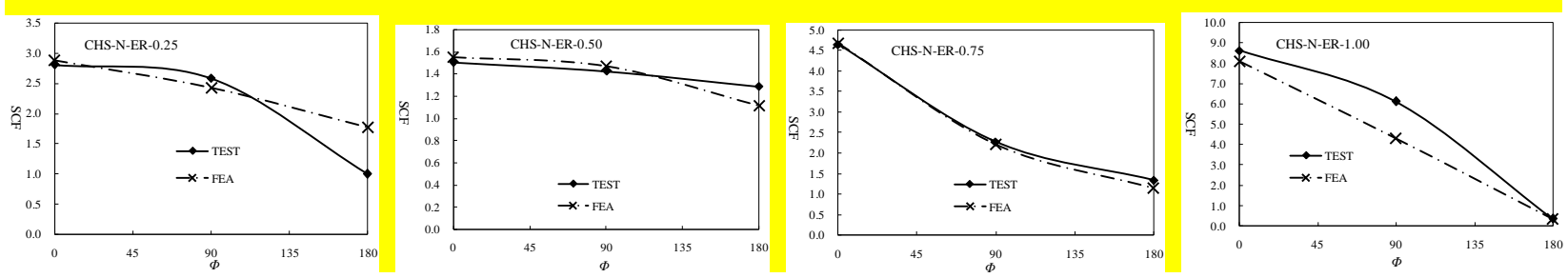

(d) Chord and inclined brace intersection near the chord intersecting line

Fig. 9. Comparison of test with FEA SCF 


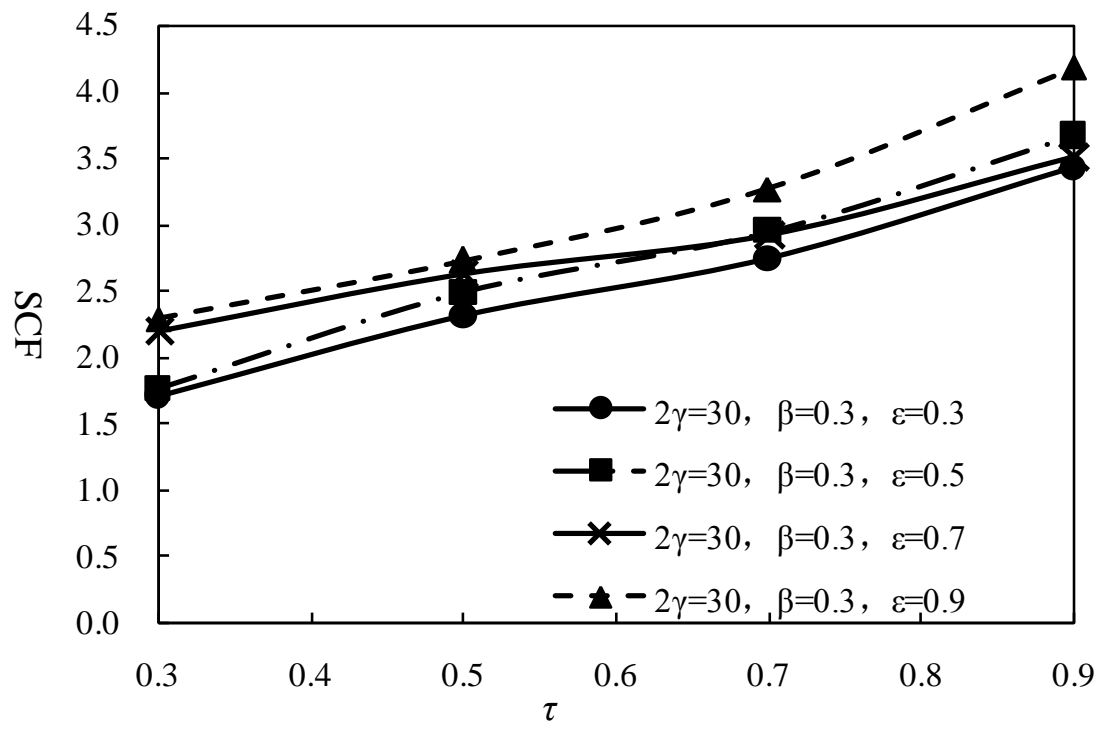

(a) The chord and vertical brace intersection welding seam near the vertical brace intersecting line

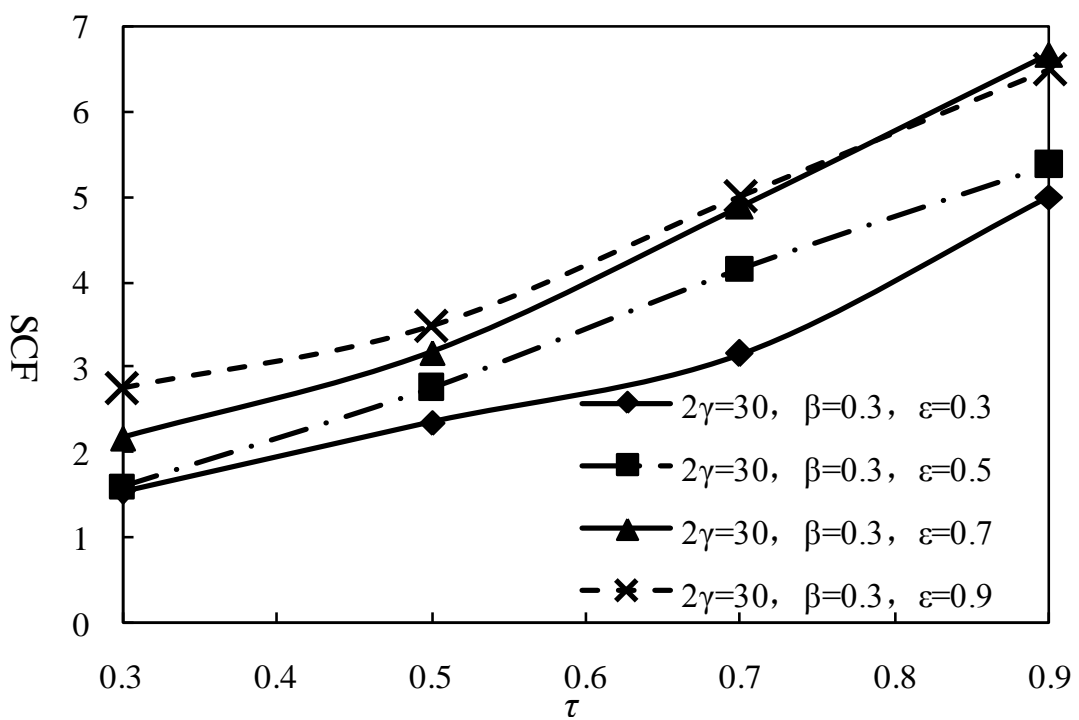

(b) The chord and vertical brace intersection welding seam near the chord intersecting line 


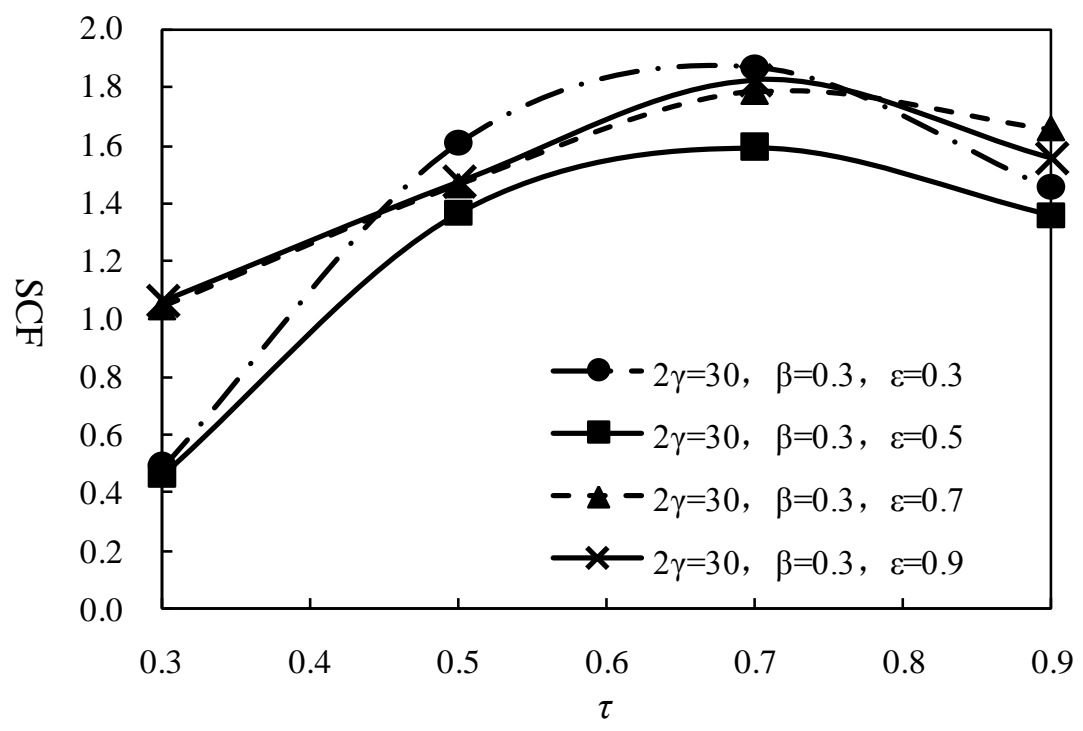

(c) The inclined brace and chord intersection welding seam near the inclined brace intersecting line

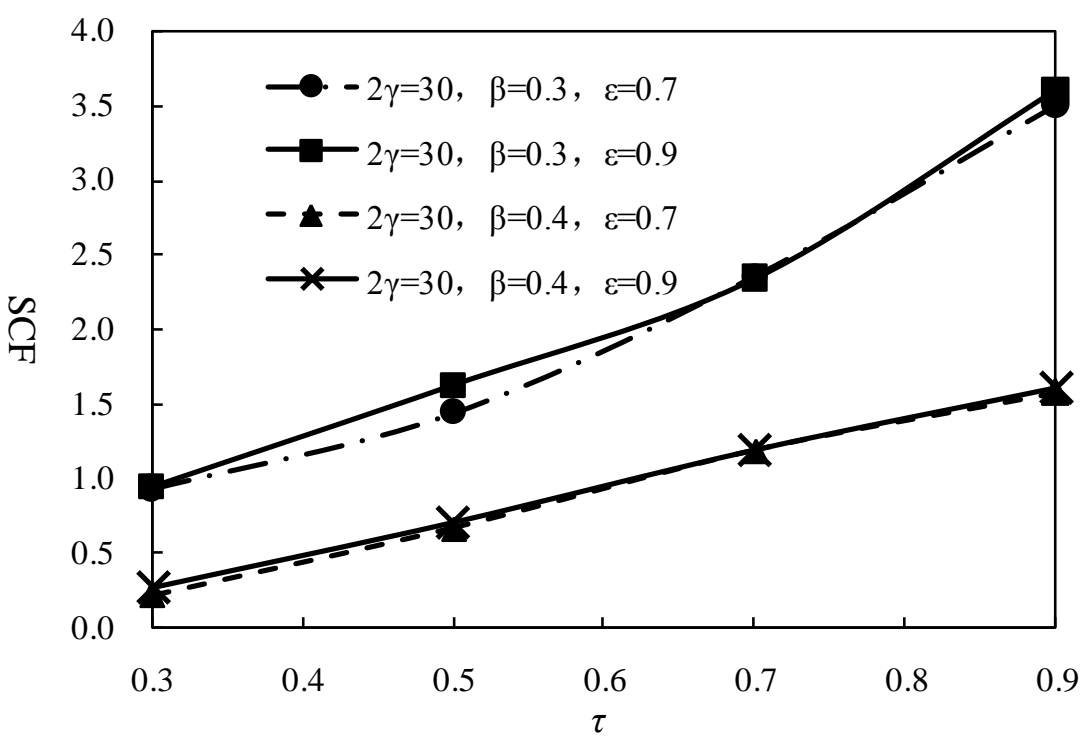

(d) The inclined brace and chord intersection welding seam near the chord intersecting line Fig. 10. Curves of SCF- $\tau$ 


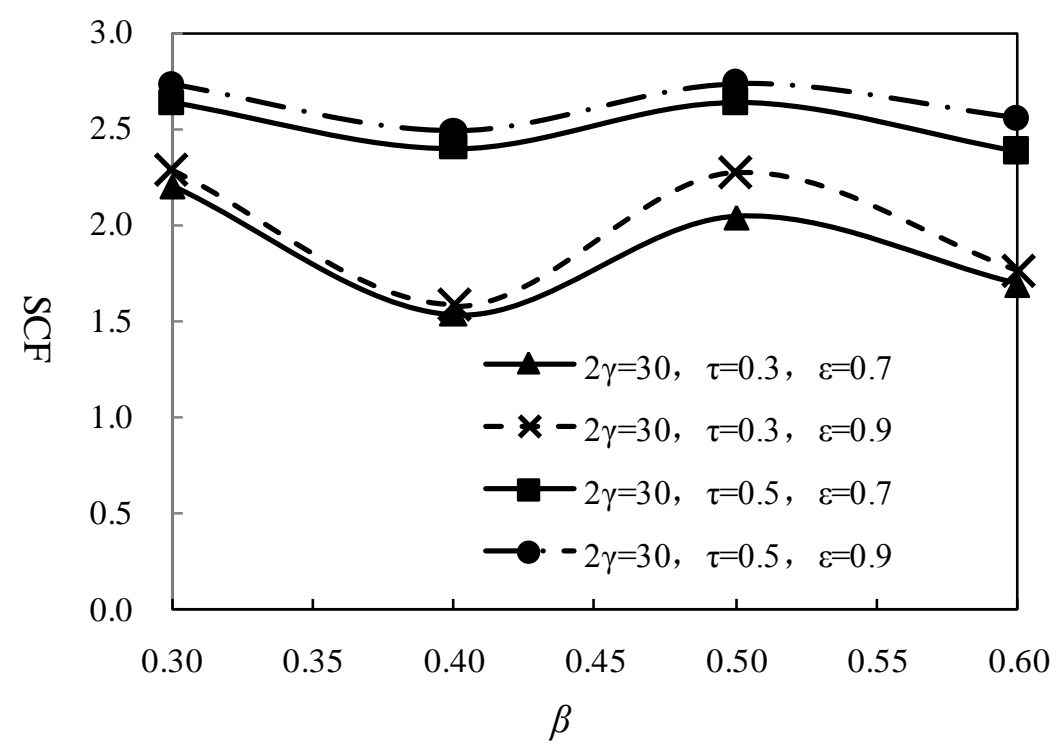

(a) The chord and vertical brace intersection welding seam near the vertical brace intersecting line

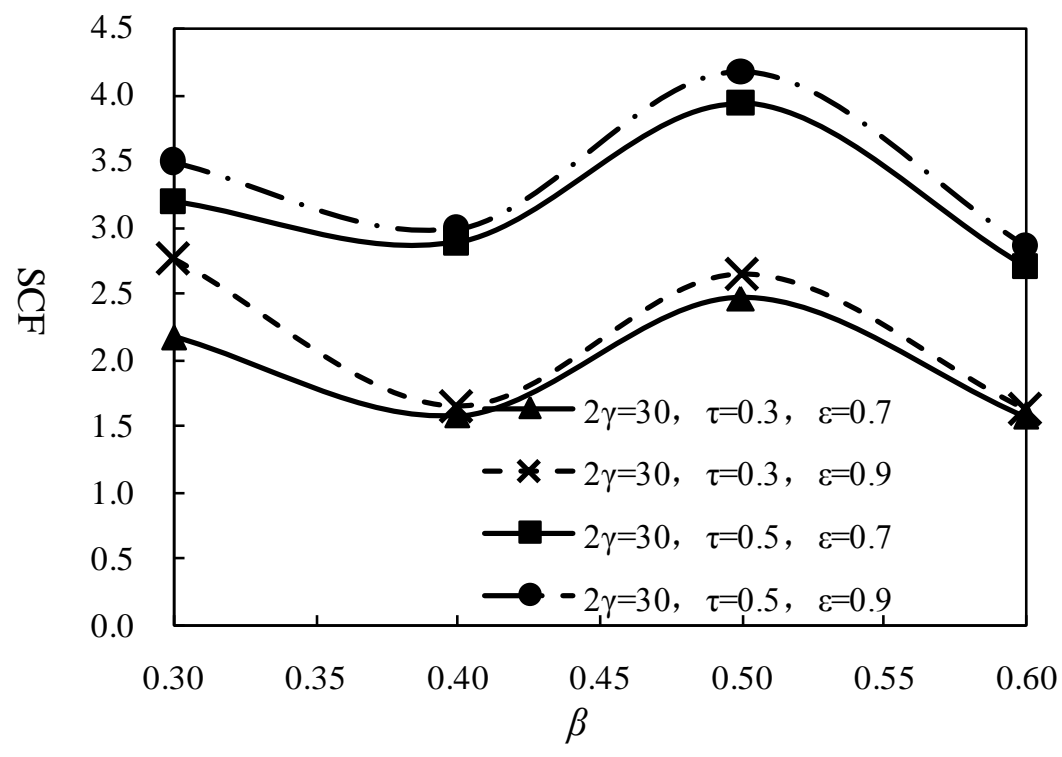

(b) The chord and vertical brace intersection welding seam near the chord intersecting line 


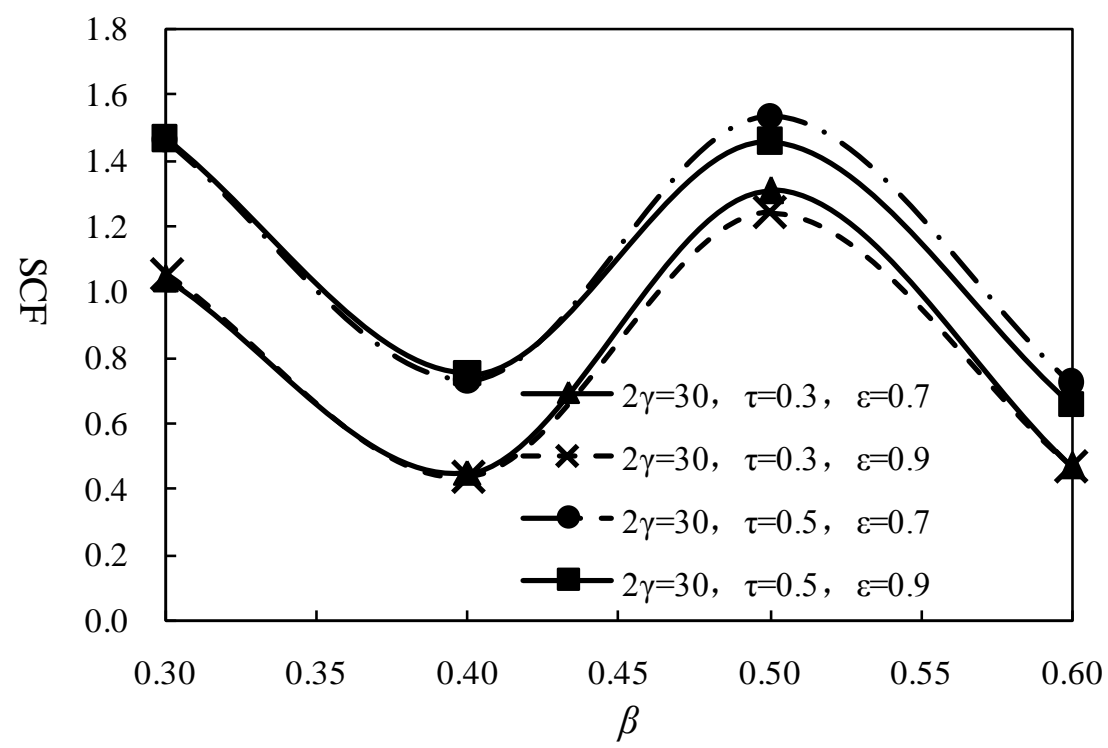

(c) The inclined brace and chord intersection welding seam near the inclined brace intersecting line

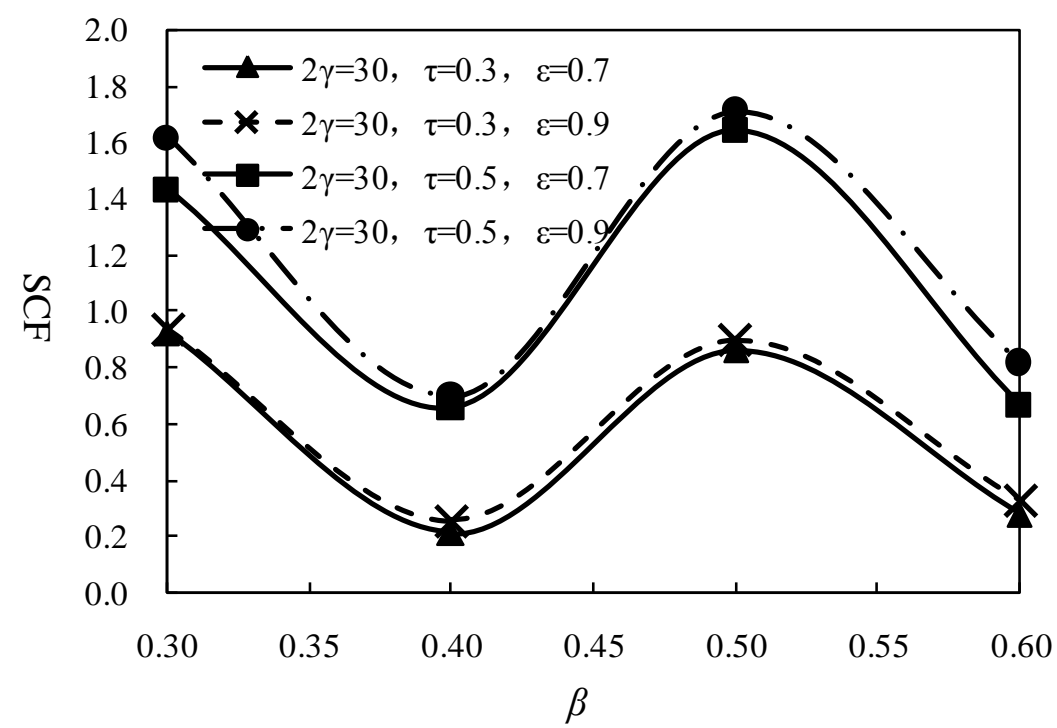

(d) The inclined brace and chord intersection welding seam near the chord intersecting line

Fig. 11. Curves of SCF- $\beta$ 


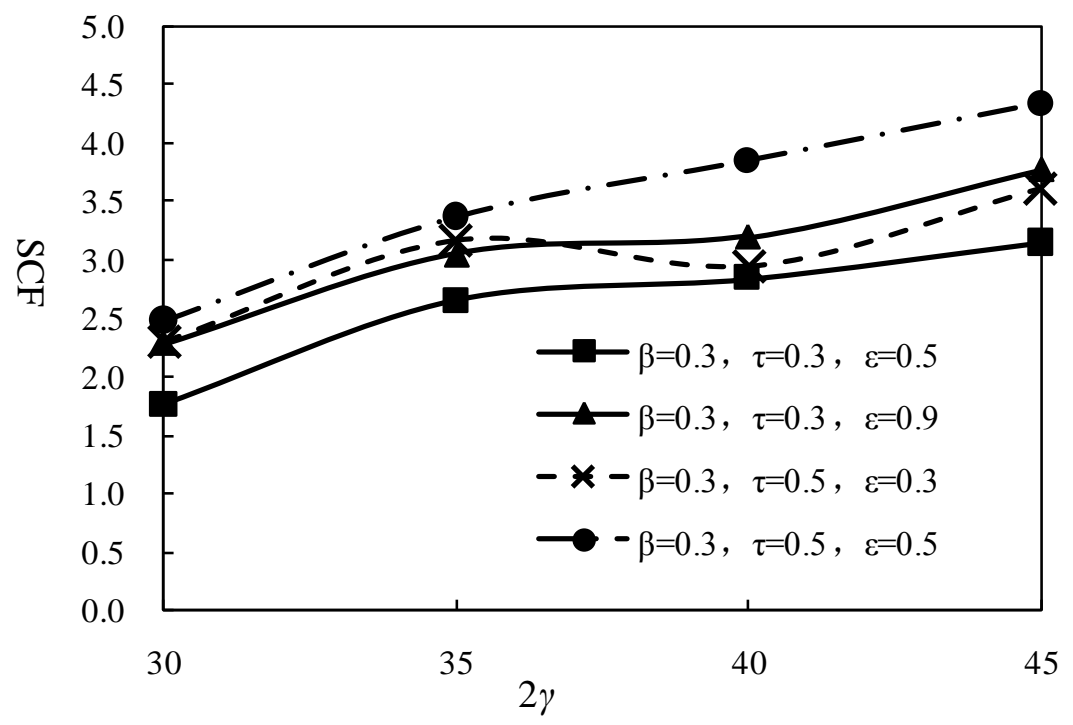

(a) The chord and vertical brace intersection welding seam near the vertical brace intersecting line

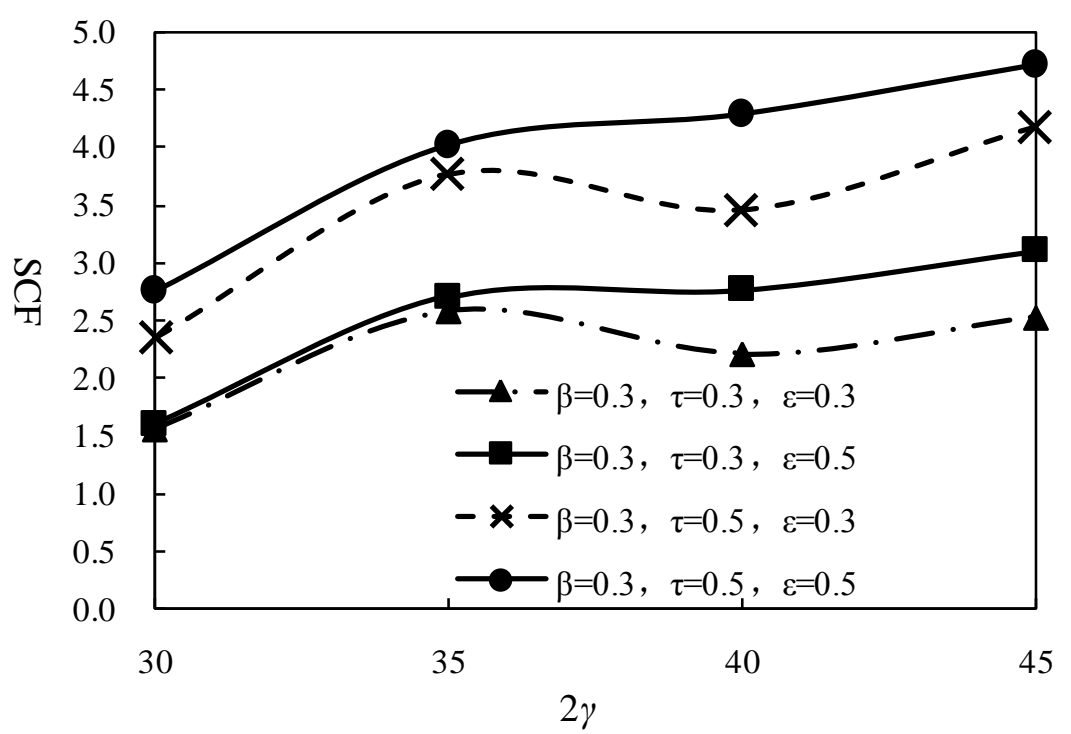

(b) The chord and vertical brace intersection welding seam near the chord intersecting line 


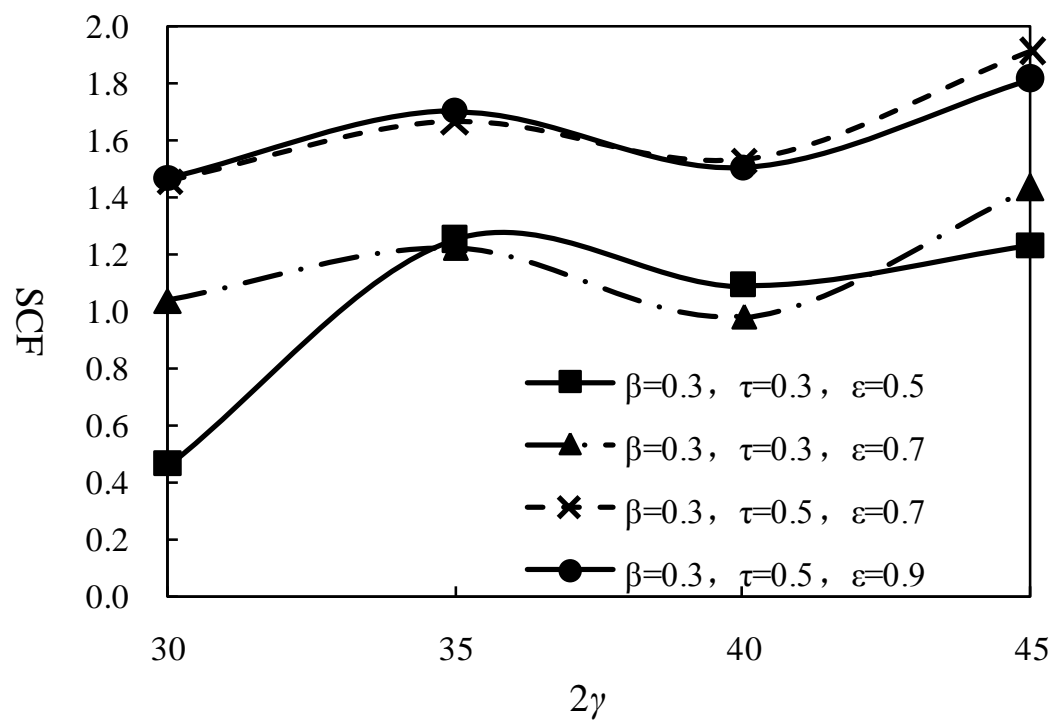

(c) The inclined brace and chord intersection welding seam near the inclined brace intersecting line

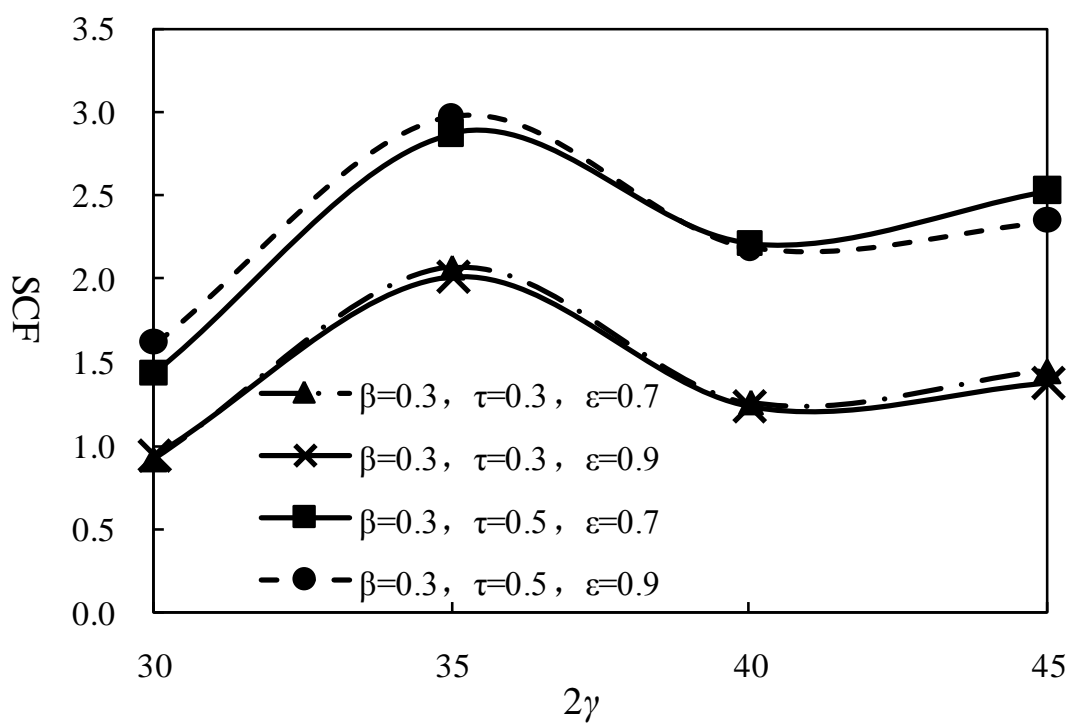

(d) The inclined brace and chord intersection welding seam near the chord intersecting line

Fig. 12. Curves of SCF-2 $\gamma$ 


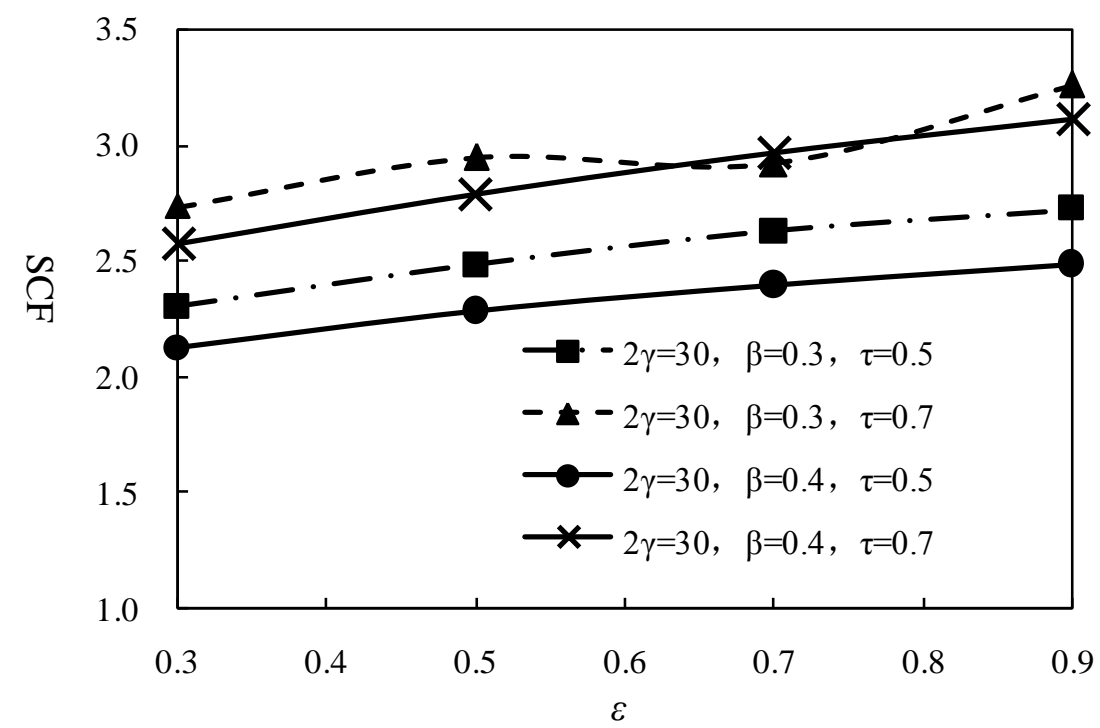

(a) The chord and vertical brace intersection welding seam near the vertical brace intersecting line

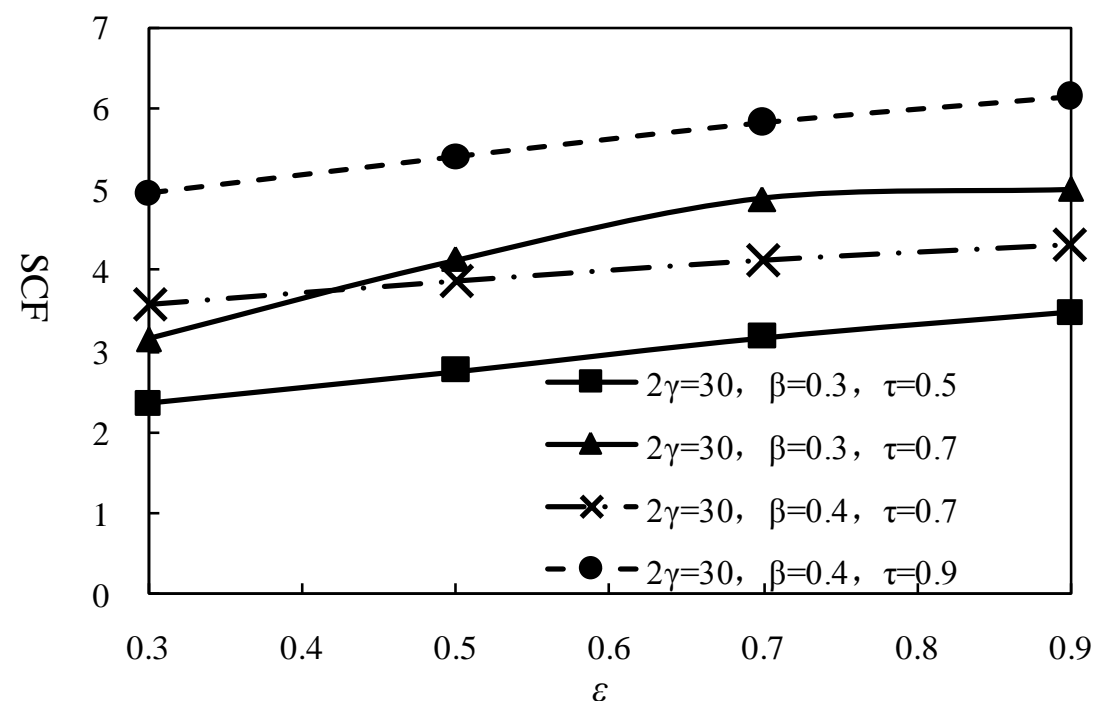

(b) The chord and vertical brace intersection welding seam near the chord intersecting line 


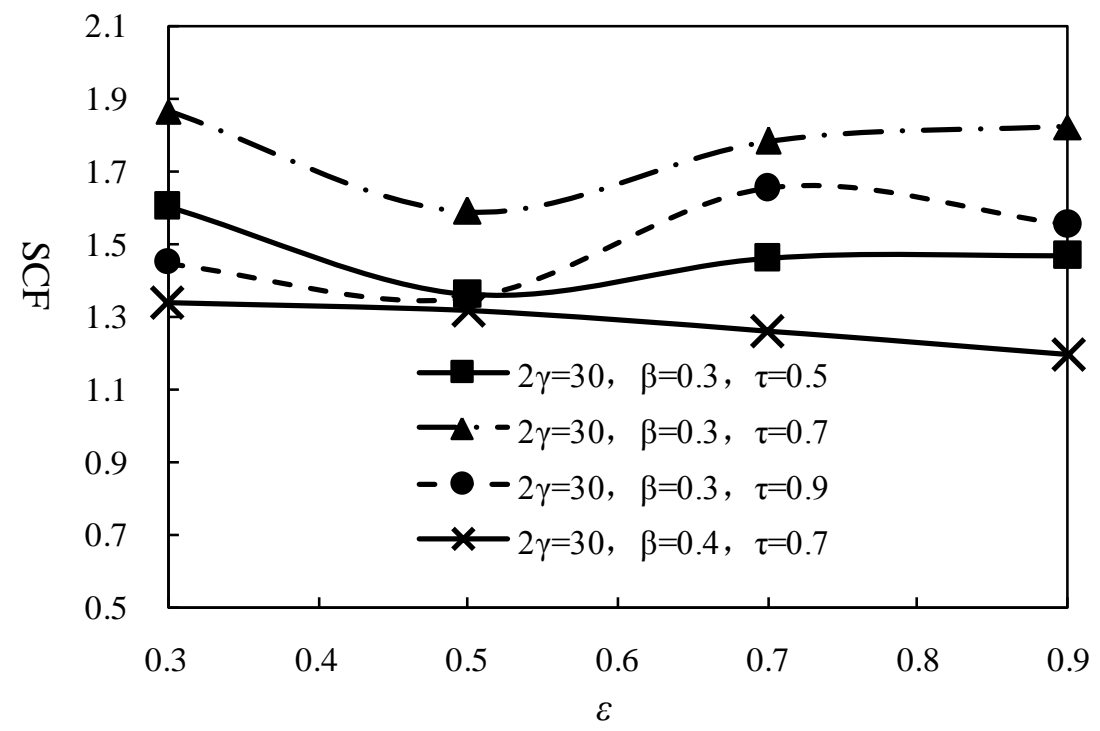

(c) The inclined brace and chord intersection welding seam near the inclined brace intersecting line

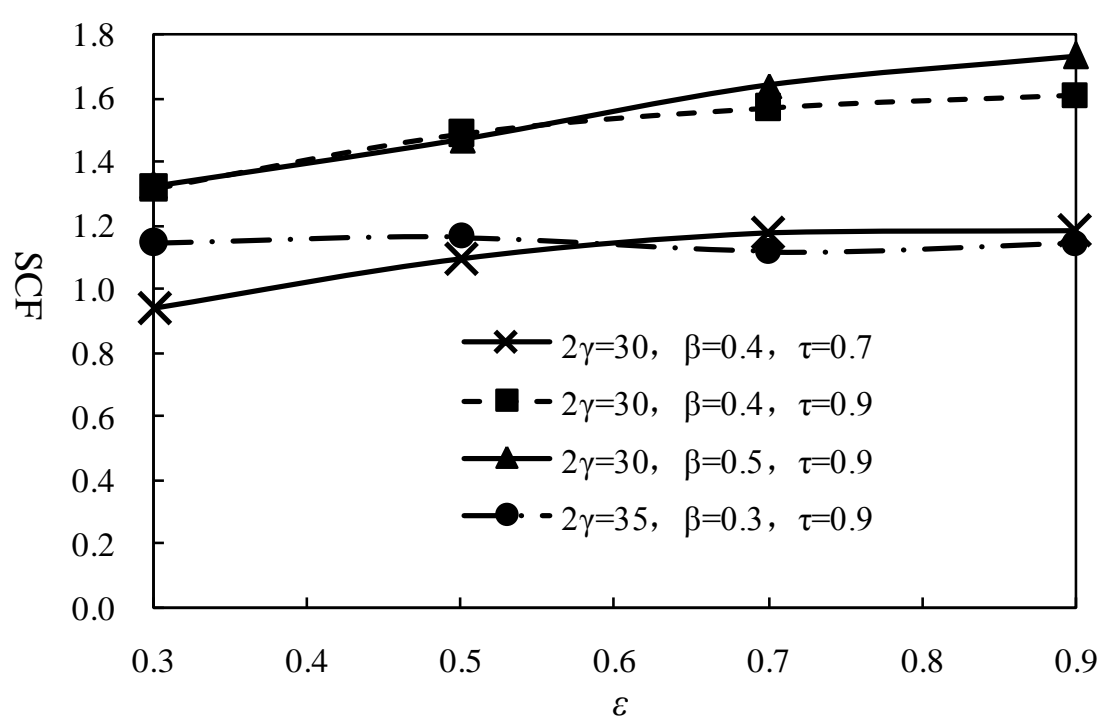

(d) The inclined brace and chord intersection welding seam near the chord intersecting line Fig. 13. Curves of SCF- $\varepsilon$ 


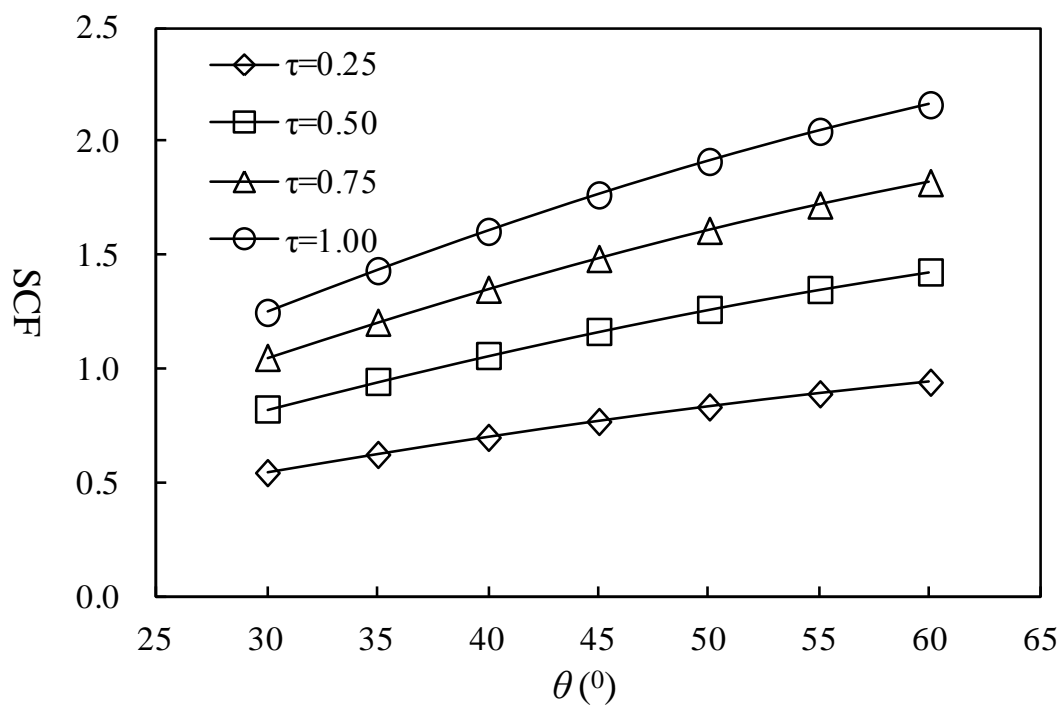

(a) The inclined brace and chord intersection welding seam near the inclined brace intersecting line

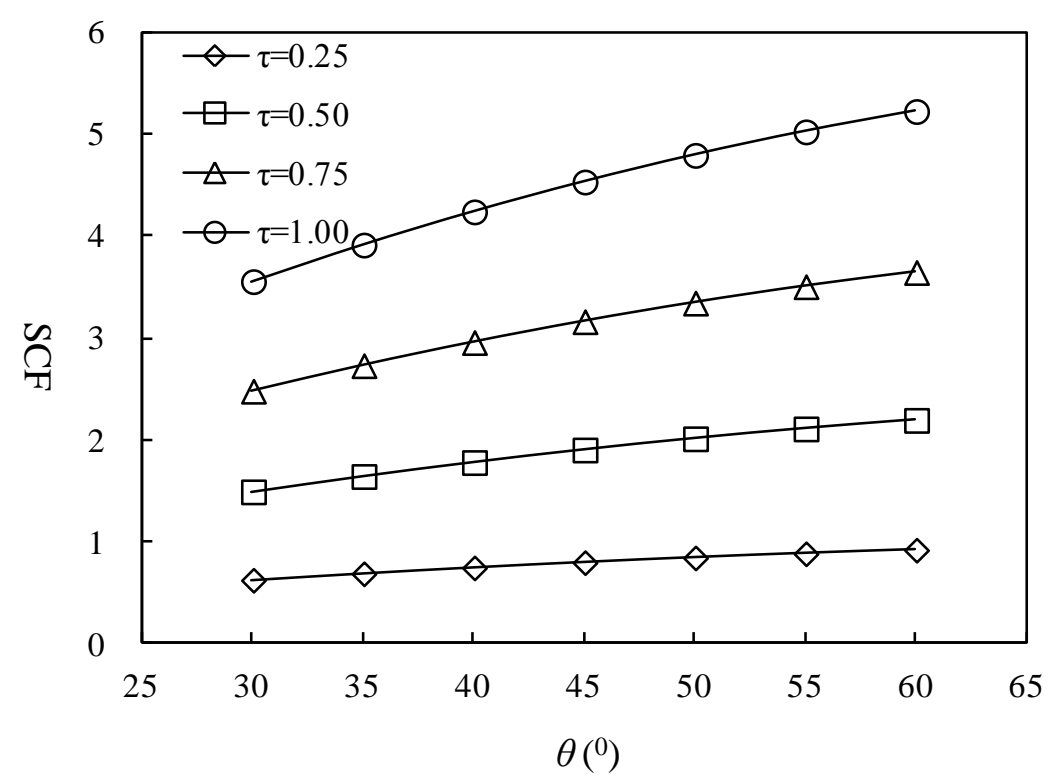

(b) The inclined brace and chord intersection welding seam near the chord intersecting line Fig. 14. Curves of SCF- $\theta$ 